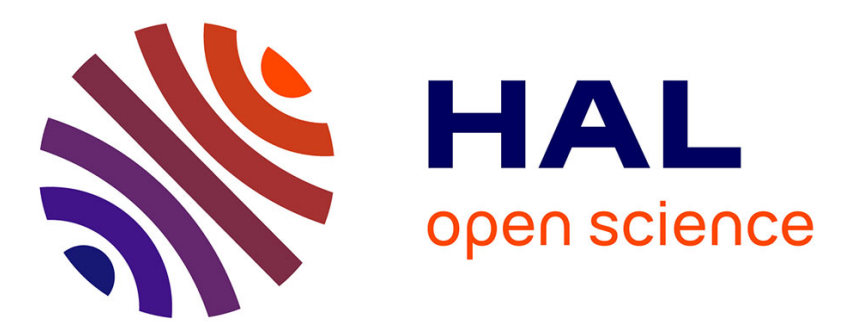

\title{
Towards a worldwide integrated market? New evidence on the dynamics of U.S., European and Asian natural gas prices
}

Raphael Chiappini, Yves Jegourel, Paul Raymond

\section{To cite this version:}

Raphael Chiappini, Yves Jegourel, Paul Raymond. Towards a worldwide integrated market? New evidence on the dynamics of U.S., European and Asian natural gas prices. Energy Economics, 2019, 81, pp.545-565. 10.1016/j.eneco.2019.04.020 . hal-03281557

\section{HAL Id: hal-03281557 \\ https://hal.science/hal-03281557}

Submitted on 25 Oct 2021

HAL is a multi-disciplinary open access archive for the deposit and dissemination of scientific research documents, whether they are published or not. The documents may come from teaching and research institutions in France or abroad, or from public or private research centers.
L'archive ouverte pluridisciplinaire HAL, est destinée au dépôt et à la diffusion de documents scientifiques de niveau recherche, publiés ou non, émanant des établissements d'enseignement et de recherche français ou étrangers, des laboratoires publics ou privés.

\section{(c) (1) $\$$}

Distributed under a Creative Commons Attribution - NonCommerciall 4.0 International 


\title{
Towards a worldwide integrated market? New evidence on the dynamics of U.S., European and Asian natural gas prices
}

\author{
Raphaël Chiappini ${ }^{1}$, Yves Jégourel ${ }^{2}$, Paul Raymond ${ }^{3}$
}

\begin{abstract}
Has the integration of European, North American and Asian natural gas markets been fostered over the last few years by growing LNG export capacities and an increasing market share of spot transactions? This is the key question that this article sets out to answer. For this purpose, we develop bivariate error correction models with structural breaks and asymmetric responses among gas references prices, oil prices, and coal prices. We use daily prices of all reference prices spanning from January 12, 2004, to January 12, 2018, for the North American, Asian and European areas. We show that if European and U.S. gas prices are co-integrated when multiple breaks are allowed, their respective markets cannot be considered integrated. However, our results show that the degree of interdependence between European and American prices is increasing, whereas the degree of interdependence between gas and crude oil prices is decreasing. More surprisingly, we also highlight that reversions to long-term equilibria both between the Henry Hub $(\mathrm{HH})$ and the National Balancing Point (NBP) and between the HH and the Japan Korean Marker (JKM) are highly asymmetric, a pattern that could be intuitively interpreted as the consequence of market arbitrage strategies by exporting countries in a context of oversupplied markets.
\end{abstract}

Keywords: Natural gas, LNG, integration, convergence, structural breaks, TECM

Code JEL: D40, L95

\footnotetext{
${ }^{1}$ Corresponding author, University of Bordeaux (France), LAREFI, raphael.chiappini@u-bordeaux.fr

${ }^{2}$ University of Bordeaux (France), LAREFI, Senior Fellow, Policy Center for the New South (Morocco), jegourel@u-bordeaux.fr

${ }^{3}$ Engie Trading, paul.raymond@engie.com
} 


\title{
Towards a worldwide integrated market? New evidence on the dynamics of U.S., European and Asian natural gas prices
}

\begin{abstract}
Has the integration of European, North American and Asian natural gas markets been fostered over the last few years by growing LNG export capacities and an increasing market share of spot transactions? This is the key question that this article sets out to answer. For this purpose, we develop bivariate error correction models with structural breaks and asymmetric responses among gas references prices, oil prices, and coal prices. We use daily prices of all reference prices spanning from January 12, 2004, to January 12, 2018, for the North American, Asian and European areas. We show that if European and U.S. gas prices are co-integrated when multiple breaks are allowed, their respective markets cannot be considered integrated. However, our results show that the degree of interdependence between European and American prices is increasing, whereas the degree of interdependence between gas and crude oil prices is decreasing. More surprisingly, we also highlight that reversions to long-term equilibria both between the Henry Hub $(\mathrm{HH})$ and the National Balancing Point (NBP) and between the HH and the Japan Korean Marker (JKM) are highly asymmetric, a pattern that could be intuitively interpreted as the consequence of market arbitrage strategies by exporting countries in a context of oversupplied markets.
\end{abstract}

Keywords: Natural gas, LNG, integration, convergence, structural breaks, TECM

Code JEL: D40, L95

\section{Introduction}

The gas market is undoubtedly experiencing profound changes due not only primarily to the development of production and export capacities for liquefied natural gas (LNG), particularly in the United States, but also to the emergence of more-flexible commercial agreements and the growing presence of physical traders. These ongoing processes might potentially have major consequences for the gas market. Through the strengthening of the LNG market, lower transaction costs and increasing flexibility, an internationally integrated gas market would clearly be a revolution. This statement would be true not only in economic terms with the assertion of new players and, most likely, a profound change in comparative advantages, but also and above all in geopolitical terms. In the short and medium term and in the economic field, two questions appear unavoidable: could these profound ongoing changes foster market arbitrage? Would they, in turn, fuel the emergence of a more integrated natural gas marketplace on a world scale? This paper sets out to answer these two interrelated central 
questions as an extension of the studies already conducted on this topic over the past few years.

There are several approaches to apprehending the reality of market integration. Kalman filters, convergence tests and cointegration measures are among the most frequent procedures used in this respect. Albeit cointegration is a statistical concept that cannot be assimilated per $s e$ with market integration, it appears reasonable to assume that prices that are determined on integrated markets should display a long-term relationship. In other words, cointegration tests can be used to measure market integration. In some cases, however, practical interpretation remains questionable. Indeed, if there is a relationship of mutual dependence between the variables studied and another variable, there might be statistical cointegration but without providing undisputable evidence that markets are integrated. Based on this approach, seminal works on natural gas market integration suggest that intra-continental markets are indeed often usually integrated (Asche et. al. 2002). However, even when cointegration relationships between the major American, European and Asian gas price references might also have been strong over a given period, such strength cannot be construed per se as a sign of a growing interconnection between markets (Brown and Yücel, 2009; Siliverstos et. al., 2005). The determining factor behind joint movements by gas prices observed in the past in the United States, Europe and Asia was not that of arbitrage between two markets but rather a certain dependence upon oil prices.

Dedicated to the analysis of natural gas market integration, this article builds directly on the groundwork laid in the above-mentioned articles by relying on cointegration measures and error correction models with three notable differences. First, our panel encompasses a very large set of natural gas daily price references in the U.S., Europe and Asia, whereas most studies considered only three prices (NBP, Henry Hub and the JKM). Second, we use the econometric procedures that allow for multiple break cointegration tests (Maki, 2012) and threshold error-correction models (Enders and Siklos, 2001). Threshold models have the advantage, contrary to Markov switching models which assume that the state process giving rise to regime switching is latent, of allowing that the nonlinear effect is driven by observable variables (Chan et al., 2017). Furthermore, cointegration tests with multiple breaks allow to detect endogenously the date of a structural change in the relationship between gas prices, and therefore, of apprehending the changing nature of the gas market over the recent period. To our knowledge, this article is the only one to date applying such econometric techniques to analyse the integration of regional gas markets. Third, our period ranges from 12/01/2004 to $12 / 01 / 2018$. This difference is anything but anecdotal, because it allows to us to consider the latest developments affecting energy markets: (1) the sharp slump in oil prices observed since the second half of 2014, which in particular is linked to the boom in unconventional gas production in the United States; (2) massive investments in the LNG industry in recent years, which translated into a growing number of liquefaction (export) plants and regasification (import) units that will enhance the capacity of international buyers to source natural gas through LNG carriers; and (3) an increased flexibility concerning LNG international trade in terms of LNG import and exports, which have historically been characterized by a high degree of rigidity, whether in terms of logistic conditions, contractual practices (incoterms) or 
pricing mechanisms. This last assertion requires a reminder of the reality of physical trade and contractual practices relating to the LNG sector. The historical structuring of natural gas markets around long-term contracts could largely be explained by the product's physical characteristics and infrastructural requirements imposed by international transportation, similar to the case of onshore gas (Asche et al., 2002). The industry's high development costs, linked significantly to the need for both liquefaction and gasification terminals and LNG carriers to transport gas by sea, create an interdependence effect between producers and users and explain the existence of long-term trade relations (Hirschhausen and Neumann, 2008; Ritz, 2014). Importing countries, largely dependent upon fossil fuels and unable to fully benefit from gas pipeline systems, thus secure their supplies, whereas for exporters, this longterm relationship is a guarantee of future revenue and the wherewithal to envision necessary logistical investments with peace of mind. Crude oil indexation is explained from two standpoints. On one side of the Atlantic, Continental Europe historically has had no gas price benchmark, with gas defined as an alternative energy to oil in the sectors of urban heating, electricity production and other industrial applications. Thus, the "oil" component in supply contracts in Europe constituted a widely accepted method of valuation for imported gas. On the other side of the Atlantic, the bridging of U.S. gas prices with oil prices is explained more by a physical connection than by any contractual requirements. As stated earlier, gas can replace oil products in a wide number of applications (for example, domestic oil and gasoil). Accordingly, the competition existing in gas markets with oil products produced the "gas" and "oil" relationship in the United States. Working under this sort of system, the LNG market has never been actually off-balance to the extent that investments in production/exportation capacities were made only when sales outlets were ensured. Fostered by the growth in anticipated long-term growth, by the idea that environmental arbitrage would favour natural gas in European countries (to the detriment of oil and coal), and by the wish of certain countries to eliminate the geopolitical restrictions that supply via gas pipelines impose, the prospects of brighter days ahead prompted producers to finance additional supply, whose price was to take shape on the spot market, most notably in the United States.

The idea was also, in certain geographic regions, to compete with the pipeline supply of natural gas, with the result that the price of LNG, through arbitrage, would be equal to the price of onshore gas once transportation and gasification were accounted for. However, once again the plot did not quite unfold as anticipated. The conjunction of the shale gas revolution in the United States, upscaling operations from historic producers such as Qatar and Australia combined with an environmental policy now much kinder to renewable energy sources than to fossil fuels, and low growth in Europe effectively created the conditions for a glut in supply that logically translated to a significant fall in gas prices and a shift in the power balance between suppliers and demanders (Rogers, 2015). Two largely interdependent consequences could be expected: stronger spot markets through an increasing importance of traded gas hubs, disconnected from oil prices, to the detriment of long-term contracts, and growing interaction between the dynamics of international prices, due not to common practices of oilrelated indexation but rather to inter-market arbitrage strategies. Empirical verification that such relationships exist has been central to many articles. As Asche et al. (2013) note, there are indeed no clear links between the existence of a spot market and the independence of gas 
prices if substitution with oil remains strong. Verifying the scope of this affirmation is therefore at the very heart of this article's ambition. Although to the best of our knowledge, no publicly available data exist that would allow us to understand explicitly the reality of commercial contracts on natural gas or, more particularly, the pricing mechanisms contained therein, there are serious reasons to believe that this trend towards greater flexibility in international trade in natural gas, via the expansion of LNG, is occurring. First, beyond the idea previously developed that excess natural gas supply has favoured the emergence of a spot market, there is indeed an obvious interest for international buyers, particularly electricity producers, in implementing these arbitrage strategies, at least on a regional scale. Such strategies can indeed be driven by not only the seasonality of the demand for gas, which leads to different peaks in demand from one country to the next, but also imperfect substitutability between gas and other energy sources in the production of electricity. This point is even truer for European markets, insofar as the regulators have vowed to foster market transparency, liquidity and completeness by means of the Gas Target Models (GTMs) I and II defined in 2011 and 2014, respectively. Nevertheless, as emphasized by Ritz (2014), producers adopting a policy of price discrimination could inversely limit intensity and thereby the effect on the interdependence of international prices. Second, physical arbitrage is now not only technologically and contractually easier but also less costly. Being by far less expensive than onshore terminals, FRSU (Floating Regasification and Storage Unit) offshore units in importing countries and, even more recently, FLNG (Floating LNG) offshore units in exporting countries, open up new prospects for international gas exchanges. FRSUs and FLNGs are, in a very simplified fashion, infrastructures located at sea to varying degrees (offshore/nearshore/inshore) whose $\operatorname{cost}^{1}$ and flexibility allow them to be considered attractive alternatives $^{2}$. Third, the rise in U.S. shale gas could, in addition to its depressing effect on world prices, also lead to an "export" of North American contractual practices that are more flexible than in the rest of the world, notably lacking the absence of so-called destination clauses, or the increased use of more flexible Free On Board (FOB) incoterm rather than Delivered Ex-Ship (DES) or Delivery at Terminal (DAT) incoterms ${ }^{3}$. For the International Energy Agency (IEA), the evidence is clear: "a new gas order is emerging, with U.S. LNG helping to accelerate a shift towards a more flexible, liquid, global market. Ensuring that gas remains affordable and secure, beyond the current period of ample supply and lower prices, is critical for its long-term prospects. LNG accounts for almost $90 \%$ of the projected growth in long-distance gas trade to 2040; with few exceptions, most notably the route that opens up between Russia and China, major new pipelines struggle in a world that prizes the optionality of $L N G$ " (IEA, 2017). In a context of sufficiently supplied markets, this new paradigm, if it were to materialize, would enshrine the role of physical traders. Drawing on their ability to

\footnotetext{
${ }^{1}$ Approximately USD 450 million, including USD 250-300 million for the "vessel" alone. An FRSU might also result from the transformation of a tanker, but the cost difference is small compared with the development of a new unit when, of course, the tanker used is new.

2 The first FRSUs were launched in 2008 in Argentina (Bahia Blanca GasPort), Brazil (Pecemport) and the United States (Northeast Gateway Deepwater Port).

${ }^{3}$ The use of the Incoterm DAT incoterm requires the definition of a delivery port, which de facto limits the buyer's capacity for physical arbitrage. An FOB incoterm or the introduction of so-called revision clauses, in contrast, allows the buyer to change the place of delivery, allowing him to limit the risk on the volume of imported gas that the seller imposes on him under a take-or-pay contract.
} 
operate these arbitrage operations to protect traditionally low intermediation margins, they would most likely make price competitiveness a key variable in the functioning of markets, which would most likely not be to the advantage of new producers ${ }^{4}$. In this context, the essential question raised by this article is not so much whether this flexibility of trade will prevail, because it is, in fact, quite consistent with the history of commodity markets, but whether it has already materialized to the point of being reflected in the joint dynamics of regional gas prices and in their links with that of oil. Linear error correction models are not sufficiently sophisticated to capture the long-term price relationships that can prevail on energy markets. Hence, many of the latest articles on gas price dynamics favour different types of regime-switching models. However, they are, to the best of our knowledge, rather focussed on the cointegrating relationships between a given crude oil price reference (West Texas Intermediate or Brent) and its "corresponding" natural gas price, primarily Henry Hub $(\mathrm{HH})$ and National Balancing Point (NBP), rather than among natural gas prices themselves. Using an error correction model with structural breaks and asymmetries in the convergence process to long-term equilibrium, this article aims at filling this gap by considering a large original dataset with information on North American, European and East Asian reference prices (i.e., the Japan Korean Marker - JKM). Oil prices are also considered to distinguish the fact that natural gas prices can display a common dependence upon crude oil rather than a "real" price comovements due to growing gas market integration. Using nonlinear error correction models that allow for both structural breaks and thresholds, we provide further evidence that European and North American markets were cointegrated prior to October 2010. However, their common cointegration with oil prices does not allow us to assert that these markets were integrated. We also demonstrate that this convergence process towards long-term equilibrium is asymmetric both between HH and NBP and between HH and the JKM, possible evidence of existing market arbitrage strategies by exporting countries.

This article is structured as follows. We initially present a rapid review of the literature focussing on the integration of gas markets and the long-term relationship between natural gas and oil prices. Next, we describe the data used for our study and specify our econometric modelling. Findings and the interpretations thereof are covered in the subsequent section. Finally, we conclude.

\section{Literature review}

The question of the integration of gas markets is not new, but no-one can deny that the selected geographic perimeter has expanded, initially favouring a national or continental dimension but now asserting itself more on a worldwide scale. In this respect, the article by Neumann (2009) is evocative of the incidence of the development of LNG production capacities on the gas market internationally.

Accordingly, the question of interconnection between gas markets for pipeline gas is anything but recent. Following Spulber and Doane (1994), Kleit (1998) effectively questioned the

\footnotetext{
${ }^{4}$ Among the most recent evidence of this increase in international traders' market power is the agreement reached between Trafigura and Chenière Energy to deliver to the independent trader one million tons of LNG per year for 15 years based on the Henry Hub spot price. This agreement is in addition to the contracts signed between Gunvor and Yamal LNG in Russia or the one allowing Glencore to source Angolan LNG.
} 
integration of gas markets within all of the various producer regions in the United States (the Rockies, Oklahoma, Texas, Louisiana and the Appalachians), a move made further to the lifting of regulations sought by the Federal Energy Regulation Commission (FERC) by way of an approach aimed at assessing the dynamics of inter-regional transaction costs. He suggested that the suppression of trade barriers does not necessarily promote the advent of a unified market. For their part, Asche et al. (2002) focussed on the integration of the German gas market by studying the dynamics of import prices from the Netherlands, Norway and Russia. Although the very idea of integration presupposes that these prices should entail virtually identical dynamics, both the nature and the diversity of international trade contracts nevertheless render more complex any apprehension of such a reality. The dominance of socalled "take-or-pay" contracts, which not only allow producers to secure commercial revenue but also provide buyers with a degree of flexibility in terms of supply volumes, has effectively led to the prevalence of price formulas that in part index the price of gas on that of gas substitutes. This indexing might explain the differences in price observed with imports, independently of the reality of market integration.

Are gas markets moving towards greater integration? This question, which implicitly queries the effect of contractual specifics tied to gas reception/delivery operations on relationships uniting the prices of gas and crude oil, actually strikes at the very heart of articles written on this subject. In this same line of thought, Brown and Yücel (2009) develop an error correction model and test the meaningfulness of cause-and-effect relationships between the prices of North American and British gas (HH and NBP) and those of WTI and Brent over the period from June 13, 1997, to May 9, 2008. Specifically, they document the asymmetry of the explanatory power of the prices of gas and oil, in which WTI and Brent prove to be explanatory variables for HH and NBP prices, respectively, but with no verification of reciprocity. Using a multi-varied model using as an explanatory variable the price of European gas (American), American gas (European), oil prices (WTI and Brent) and the vectors of joint integration between oil and gas prices, the authors show that gas prices adjust to the discrepancies in the long-term relationship maintained with WTI. In other words, the joint dynamic of gas prices on either side of the Atlantic is explained more by a shared dependency upon the price of crude oil than on arbitrage operations due to LNG between the United States and the United Kingdom, in accordance with the previous findings of Brown and Yücel (2009). Although Li et al. (2014) also question the international integration of gas markets by extending their analysis to the Asian zone (Japan, South Korea and Taiwan), the econometric procedures they use are different because of the intrinsic limitations of cointegration analyses in addressing issues of convergence. Adopting the Philips-Sul test and the Kalman filter to apprehend the (gradually) changing nature of relationships between several series, the authors show that there is no global integration of the markets. They show that integration is rather gaining strength, between not only the three Asian markets under consideration but also these markets and the British gas market, thereby leaving the North American market to adopt its own specific dynamic.

The question of market integration is by its nature a structural one and should consequently be considered in the long term, which in turn raises questions about the stability of the 
cointegrating relationships not only between oil and gas prices but also between gas prices themselves. This point is even truer when one examines the last decade, in which oil prices severely decoupled from gas prices ${ }^{5}$ in the aftermath of the 2008 financial crisis and the U.S. shale gas revolution, as they did in the U.S. in the eighties and the nineties. Technological changes, notably the growing role of not only combined cycle gas turbines since the 1990s but also the more recent horizontal drilling and rock fracturing techniques, could indeed explain that the relative prices of natural gas to crude oil change considerably over time. This change implies that any studies based on linear error correction models could be methodologically flawed (Ramberg and Parsons, 2012). Regime-switching models have therefore been adopted to overcome this type of misspecification. For instance, Brigida (2014) develops an error correction model with endogenous shifts in cointegrating vector determined by a first-order Markov process. Considering the period from September 1997 to September 2012, the author tests the fact that the long-term relationship between the WTI front month prices and HH gas price can experience structural breaks, once variables such as temperature variations or the U.S. field production of crude oil are controlled for. One of the main conclusions of this article is that oil and gas prices did not permanently decouple in the 2000s but rather exhibited a disconnection from August 2000 to May 2009 during which HH prices outperformed oil prices.

Asche et al. (2017) also criticize the conventional "error correction model approach" but for its inability to consider the fact that natural gas prices periodically decouple from oil prices during fall and early winter seasons at a time when immediate demand for heating can be sufficiently high to reach the maximum utilization pipeline capacity, allowing for specific gas pricing and consequently leaving little room for oil indexation to influence prices. Using both a linear error correction model that averages natural gas prices and a Markov-switching model, in line with Bridiga (2014) methodology but which allows for potential peak loading pricing, the authors consider the dynamics of the InterContinental Exchange (ICE) front month gas prices ${ }^{6}$ and the Brent front month prices on a weekly basis. They show that the use of a linear model combined with the prevalence of decoupling underestimates not only the adjustment to deviations from the equilibrium relationship but also the long-term equilibrium relationship between oil and natural gas prices. Addressing these biases through a regimeswitching model that allows for a two-state dependency (gas pricing being either oil driven or specific), the authors demonstrate that oil and UK gas markets appear to be integrated for the majority of the considered period.

The approach developed by Barnes and Bosworth (2015) prefers a radically different form of modelling based on equations of gravity that is very widely seen in the empirical analysis of international trade flows. The authors' approach is to identify the determinants of import and export flows of LNG and compressed natural gas (CNG) to estimate the incidence of the "distance" variable on the intensity of bilateral trading and thereby apprehend the regional, or inversely the international, dimension of the gas market. The results obtained by Barnes and Bosworth (2015) confirm the importance of distance as an explanatory component of CNG

\footnotetext{
${ }^{5}$ As measured by the crude oil to natural gas price ratio.

${ }^{6}$ The ICE natural gas contracts delivery point is at the UK National Balancing Point Hub.
} 
trading, as opposed to LNG. Two conclusions can be drawn here: LNG might well be a global market, something the CNG market cannot claim to be, and its strong growth is aiding the internationalization of the natural gas market. Ritz (2014) adopts an idea that is equally different from those based on the analysis of co-integration relationships between gas prices observed at reference hubs. He effectively considers that due to the adoption of strategic behaviours by producers in certain markets, there are intrinsic limits to arbitrage operations. If producers embark upon a third-order policy of price discrimination, in principle, there is therefore no reason to consider that the integration of gas markets should translate to an equalization of prices once transportation costs have been accounted for.

\section{Data and empirical methodology}

\subsection{Data}

Our aim is to evaluate both the integration of the European gas market and the world gas market, controlling for the relationship between gas and oil prices. For this purpose, we use daily data at business frequency, expressed in euro per megawatt-hour (MWh) ${ }^{7}$, from Thomson Reuters for the NBP in the United Kingdom and all other European gas prices, such as the Central European Gas $\mathrm{Hub}\left(\mathrm{CEGH}^{8}\right)$ in Austria, the Title Transfer Facility (Netherlands), the French "Points d'Echange de Gaz"" (North and South), the Net Connect Germany (NCG), the Gaspool (Germany) and the Zeebrugge hub in Belgium. Referred to collectively as "hubs", they have neither the same economic role nor the same economic importance; the historical domination of the NBP explains why almost all empirical papers addressing European gas markets have neglected the aforementioned European continental hubs. Heather $(2012,2015)$ thus distinguishes between trading (NBP and TTF), transmission (NCG, and PEG North and South) and transit (ZEE and CEGH) hubs. Albeit other hub prices

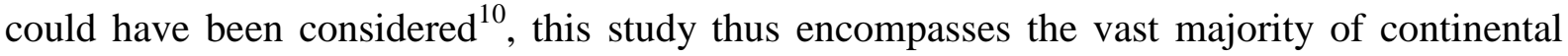
gas prices and distinguishes itself from existing studies in this respect. We also use daily data for the $\mathrm{HH}$, the Japan-Korean marker, oil and coal prices. A point must be made concerning the oil price series chosen here. In contrast to existing empirical papers relying on weekly or monthly time series of Brent or WTI front month prices, we opt for a "long-term oil index", which is simply a six-month moving average of Brent daily prices. The primary reason for this choice is that long-term sales agreements on natural gas, which are indexed on crude oil prices, largely rely on a price formula and not on weekly or monthly oil prices as such. Based on industry practices, this six-month moving average time series appears to be a much more reliable indicator of a potential common dependence upon oil prices than are the raw data ${ }^{11}$.

\footnotetext{
${ }^{7} \mathrm{NBP}$, Henry Hub and JKM prices are converted into euro using the daily pound-euro exchange rate and the daily euro-dollar exchange rate.

${ }^{8}$ Formerly known as Baumgarten.

${ }^{9}$ Literally "Gas Exchange Point".

${ }^{10}$ Such as the "Punta di Scambio Virtuale" in Portugal.

${ }^{11}$ Hence, according to a " 6.1 .6 sell/purchase agreement", natural gas is bought at $\mathrm{t}_{0}$ by an electricity producer at a six-month moving average price and sold at the same price (+margin) for next six months, the deal being on the table for one month.
} 
We also choose to consider the API2 coal price ${ }^{12}$ whereas previous studies do not. The main reason for that choice is that, akin to oil, natural gas has proved a substitute to coal-fired thermal plants. According to the so-called clean dark spread (CDS) and clean spark spread, i.e., the difference between the price at which electricity can be sold to the grid and the costs to produce it either by consuming natural gas or coal once the environmental aspects are considered, there is a price for natural gas under which power companies will favour natural gas rather than coal. The time span of this rich dataset differs according to the prices under consideration. For most prices, we use data from 12/05/2004 to 12/01/2018. For PEG North, NCG, CEGH and PEG South however, our time series start respectively with $02 / 12 / 2005$, $02 / 10 / 2007,15 / 09 / 2009$ and 09/29/2009. Note that Coal data only start from the 18/08/2006.

Table 1 presents descriptive statistics of the logarithm of the different prices under consideration in this paper, and Figures 1,2 , and $3^{13}$ present the evolution of the different prices in the level.

Table 1. Descriptive statistics of natural gas, oil and coal prices

\begin{tabular}{|c|c|c|c|c|c|c|c|c|c|c|}
\hline & Mean & Median & Max. & Min. & $\begin{array}{c}\text { Std. } \\
\text { Dev. }\end{array}$ & kew. & urtosis & JB & Obs. & Start Date \\
\hline $\begin{array}{l}\text { Belgium } \\
\text { (ZEE) }\end{array}$ & 2.893 & 2.947 & 4.565 & 0.908 & 0.350 & -0.277 & 3.210 & 67.851 & 4648 & $12 / 01 / 2004$ \\
\hline (TTF) & 2.885 & 2.950 & 4.060 & 0.875 & 0.326 & -0.490 & 2.615 & 215.022 & 4648 & $12 / 01 / 2004$ \\
\hline U.K. & 2.891 & 2.937 & 4.569 & 0.742 & 0.359 & -0.305 & 3.342 & 94.923 & 4648 & $12 / 01 / 2004$ \\
\hline $\begin{array}{l}\text { Germ } \\
\text { (Gast } \\
\text { Germ }\end{array}$ & 0 & 2.958 & 54 & 6 &  & ) & 6 & & 4648 & 04 \\
\hline $\begin{array}{l}\text { (PEC } \\
\text { Fran }\end{array}$ & .970 & 3.045 & 4.190 & 1.841 & 0.320 & -0.593 & 93 & 234.346 & 4000 & 2005 \\
\hline $\begin{array}{l}\text { (PEG-South) } \\
\text { Austria }\end{array}$ & 3.052 & 3.094 & 3.773 & 1.821 & 0.290 & -0.568 & 3.245 & 151.010 & 2682 & $26 / 09 / 2009$ \\
\hline $\begin{array}{l}\text { (CEGH) } \\
\text { U.S. (Henry }\end{array}$ & 3.034 & 3.084 & 3.689 & 2.327 & 0.243 & -0.773 & 2.698 & 278.156 & 2693 & $15 / 09 / 2009$ \\
\hline $\begin{array}{l}\text { Hub) } \\
\text { Japan- }\end{array}$ & 2.770 & 2.659 & 3.963 & 2.021 & 0.362 & 0.619 & 2.899 & 298.375 & 4648 & $12 / 01 / 2004$ \\
\hline Korean & 3.243 & 3.237 & 3.928 & 2.220 & 0.435 & -0.330 & 2.094 & 151.770 & 2903 & $02 / 02 / 2009$ \\
\hline Oil & 3.124 & 3.125 & 3.565 & 2.197 & 0.319 & -0.699 & 3.184 & 384.687 & 4648 & $12 / 01 / 2004$ \\
\hline Coal & 4.164 & 4.120 & 4.956 & 3.631 & 0.250 & 0.434 & 2.866 & 120.634 & 3754 & $18 / 08 / 2006$ \\
\hline
\end{tabular}

Note: All variables are expressed in the logarithmic form. JB denotes the Jarque-Bera statistic

European gas prices blatantly exhibit very similar characteristics, particularly German (Gaspool), Belgium (ZEE), Dutch (TTF) and British (NBP) natural gas prices, suggesting that the difference between those prices could be marginal. The existence of continental interconnectors combined with the fact that some hubs play a leading role in gas contract pricing compared to others, is one of the obvious explanations for this similarity. The pricing role of natural gas exchanges, such as Powernext, the European energy exchange (EEX) or

\footnotetext{
${ }^{12}$ i.e., the benchmark price reference for coal imported into northwest Europe.

${ }^{13}$ See Appendix.
} 
the ICE in Europe, is also part of the answer. In contrast, Figure 2 suggests a different evolution for NBP, Henry Hub and the JKM. We can remark on a similar pattern for NBP and Henry Hub until 2010, with a higher volatility for NBP. However, at the end of 2010, Henry Hub, the JKM and NBP appear to decouple and exhibit very different patterns. Finally, after 2015, these three prices appear to recouple and to follow a similar evolution. Figure 3 offers evidence of a similar trend between NBP and oil prices, whereas the relationship with coal prices appears more difficult to identify.

\subsection{Empirical methodology}

In this paper, we are interested in the integration of the world gas market. In particular, we aim to distinguish a cointegration relationship between natural gas and oil prices due to world market integration. Furthermore, the paper is also dedicated to a potential effect of LNG on the European gas market. To achieve this purpose, we rely on different econometric approaches, from linear cointegration tests to a vector error-correction model with structural breaks. We also implement threshold cointegration. All models considered in this study are bivariate models. However, before using cointegration methods, we must test the order of integration of gas, oil, and coal prices.

\subsubsection{Structural change and unit root tests}

Before proceeding to the cointegration tests, the properties of the time series must be studied. For this purpose, we apply Augmented Dickey-Fuller (ADF) to test the order of integration of each variable retained in the analysis. For a robustness check, we complement this test with the stationarity test developed by Kwiatkowski, Phillips, Schmidt and Shin (1992), which tests the null hypothesis of stationarity instead of the existence of a unit root as in the ADF and PP tests. Using both types of test is important because the ADF test has low power if the process is stationary, but with a root close to the non-stationary boundary, the test tends to reject the non-stationarity hypothesis too often. The KPSS complements the ADF test because, in contrast to the latter, which assesses the null hypothesis of the unit root, the former tests the null hypothesis of stationarity. It is a very powerful test, but it cannot catch non-stationarity due to a volatility shift.

Because we employ data on a very long-time span (14 years), gas, oil and coal prices series can however contain a variety of structural changes due to economic, political or external shocks in the long term. Figures 1, 2, and 3 confirm multiple structural changes in the series under scrutiny. However, if the presence of structural breaks in the series is not considered when using unit root tests, this can lead to misspecification errors (Ketenci, 2016). Consequently, we rely on the Perron and Yabu (2009) test to determine whether there are any structural changes in the deterministic components of a univariate time series. This test can be applied when whether the series (here different prices) is trend stationary or contains an autoregressive unit root is a priori unknown. Perron and Yabu (2009) develop a test of the null hypothesis of no structural change in the deterministic components and employ the test statistic Exp- $\mathrm{W}_{\mathrm{FS}}$ based on robust quasi-flexible generalized least squares (FGLS). Three models can be used for the estimation: the first model testing for the presence of a structural break in the level of a variable (model I), the second model testing for a shift in the slope of 
trend (model II) and the third model testing for structural changes in both the level and the slope of the time trend.

If the presence of a structural break is detected in the deterministic components, standard unit root tests such as ADF or KPSS can lead to inconsistent results. Several tests have been implemented in the empirical literature to consider the existence of breaks in time series. The most commonly used tests are those from Zivot and Andrews (1992), allowing for one break, and from Lee and Strazicich (2003), allowing for two breaks. However, both tests assume that the break occurs only under the alternative hypothesis of stationarity. This result is undesirable, particularly if the Perron and Yabu test suggests a structural change in time series. Kim and Perron (2009) propose a new method that allows a break at an unknown time under both the null and the alternative hypotheses. Carrion-i-Silvestre et al. (2009) extend this methodology and develop a test that permits up to five breaks at unknown times in both the level and slope of the time trend. Their test is based on a quasi-generalized least squares (GLS) detrending method proposed by Elliott et al. (1992) that allows tests to have a local asymptotic power function close to the local asymptotic Gaussian power envelope. Therefore, if the presence of a structural change in a time series is confirmed by the test of Perron and Yabu (2009), we rely on the Carrion-i-Silvestre et al. (2009) unit root test.

In this paper, we use the model III of the Perron and Yabu (2009) test, which corresponds to the model III of the Carrion-i-Silvestre et al. (2009) test. Indeed, as depicted in Figures 1, 2, and 3, it appears that all series have experienced multiple structural changes in both intercept and time trend.

\subsubsection{Structural breaks and cointegration}

Standard cointegration tests enable verification of the existence of the law of one price (LOP) and thus the perfect integration of markets. Under this approach, identical goods traded at different locations in an integrated market must have the same long-term price once transport and other transfer costs are considered. However, explanatory power of standard linear cointegration tests could nonetheless be strongly affected by the presence of breaks in the level, trend, or slope coefficients in the cointegration relationship because it changes the asymptotic distribution of the test (Perron, 1989). Moreover, Gregory and Hansen (1996a) have demonstrated that the null hypothesis of no cointegration might not be rejected when the cointegrating relationship is unstable. Therefore, standard cointegration tests could lead to accepting the null hypothesis of no cointegration between gas prices only because there is a break in the level function in the long-term relationship. Therefore, the test could lead to rejecting the hypothesis of an integration of the natural gas market. Indeed, as depicted in Figures 1, 2 and 3 in the Appendix, gas prices have experienced structural changes; the relationships between these prices could have evolved through time, for instance with a decrease in transportation costs.

Consequently, Gregory and Hansen (1996a, 1996b) have developed a residual-based test that allows addressing shifts in both level and trend. The procedure tests the null hypothesis of no cointegration against the alternative of cointegration in the presence of level shift (Model 1); level shift with trend (Model 2); and regime shift, in which intercept and slope coefficients 
change (Model 3). Furthermore, Gregory and Hansen (1996b) add a more general formulation of the test by specifying a regime shift in which intercept, slope coefficients and trend change (Model 4) in the alternative hypothesis. In the case of testing cointegration between two prices, the model can be written as follows:

$$
P_{t}^{1}=\beta_{1}+\beta_{2} \varphi_{t k}+\alpha_{1} t+\alpha_{2} t \varphi_{t k}+\mu_{1}^{T} P_{t}^{2}+\mu_{2}^{T} P_{t}^{2} \varphi_{t k}+\varepsilon_{t}
$$

where $P_{t}^{1}$ and $P_{t}^{2}$ are the logarithm of prices (gas, oil or coal), $\beta_{1}, \mu_{1}$ and $\alpha_{1}$ the intercept, slope coefficients, and trend coefficient, respectively, before the regime shift, and $\beta_{2}, \mu_{2}$ and $\alpha_{2}$ are the corresponding changes after the break. Note that:

$$
\left\{\begin{array}{l}
\varphi_{t k}=0 \text { if } t \leq[n \tau] \\
\varphi_{t k}=1 \text { if } t>[n \tau]
\end{array}\right.
$$

where $\tau$ denotes the timing of the changing point, and [] denotes integer part.

The test statistics for the Augmented Dickey Fuller (ADF) and $\mathrm{Z}_{\mathrm{a}}$ and $\mathrm{Z}_{\mathrm{t}}$ of Perron are:

$$
A D F^{*}=\operatorname{Inf} f_{\tau \in T} A D F(\tau), Z_{a}^{*}=\operatorname{In} f_{\tau \in T} Z_{a}(\tau) \text { and } Z_{t}^{*}=\operatorname{In} f_{\tau \in T} Z_{t}(\tau) .
$$

In this paper, we initially rely on the test proposed by Gregory and Hansen (1996b) based on model 4.

However, the test developed by Gregory and Hansen only allows testing for one structural break in the alternative hypothesis. Maki (2012) proposed a new cointegration test that allows identifying up to five different unknown breaks. The test is a residual-based model that assumes that the maximum number of breaks of the cointegrating vector is less than or equal to the maximum number of breaks. Maki (2012) provides evidence that the case of one break is consistent with the cointegration models of Gregory and Hansen (1996a, 1996b), whereas the case of two breaks is similar to the model of Hatemi-J (2008). Furthermore, using Monte Carlo simulations, Maki (2012) shows that the proposed tests perform better than do the tests of Gregory and Hansen (1996, 1996b) and Hatemi-J (2008) when three breaks or more are considered in the cointegration relationship.

Maki (2012) proposes four different models to test for cointegration with multiple breaks. The first one assumes multiple breaks in the intercept without trend, the second one assumes multiple breaks in both intercept and slope coefficients without trend, the third model assumes multiple breaks in intercept and slope coefficients with a time trend, and the fourth one assumes multiple breaks in intercept, slope coefficients and trend. The last model can be expressed as follows:

$$
P_{t}^{1}=\beta_{1}+\sum_{i=1}^{k} \beta_{2, i} \varphi_{i, t}+\alpha_{1} t+\sum_{i=1}^{k} \alpha_{2, i} t \varphi_{i, t}+\mu_{1}^{T} P_{t}^{2}+\sum_{i=1}^{k} \mu_{2, i}^{T} P_{t}^{2} \varphi_{i, t}+u_{t}
$$

where $\varphi_{i, t}$ represents dummy variables equal to 1 if $t>T_{B, i}$ and $T_{B, i}$ denotes the period of the break. Note that $k$ is the maximum number of breaks, which is set to 5 . Finally, all variables must be I(1) for the implementation of the Maki (2012) cointegration test. 
However, the assumption of a perfect integrated market, i.e. the verification of the LOP, must also be tested. If the LOP is verified, any differences between prices will lead to arbitrage opportunities, and prices will consequently converge a single value (Nick and Tischler, 2014). Nevertheless, although this theory assumes no transaction costs, they are of high importance, particularly in the gas market. Therefore, a price spread between two markets will converge towards transaction costs. In this case, there exist arbitrage opportunities if the price in market $i$ is different from the price in market $j$ once transaction costs are considered, such as:

$$
\left\{\begin{array}{l}
P_{i}>P_{j}+\varphi \\
P_{i}<P_{j}-\varphi
\end{array}\right.
$$

Thus, any decrease in transaction and transfer costs $(\varphi)$, such as innovations that permit dropin transportation costs, will decrease the price spread between two markets. Indeed, transportation costs can justify differences in natural gas prices between two different geographic areas, for example the Asian and European markets. Following Asche et al. (2002) and Siliverstos et al. (2005), we construct a Wald test and restrict the cointegrating vector between a pair of prices as $\beta=(1 ;-1)$, including an intercept in the long-run relationship, to test this hypothesis.

\subsubsection{Threshold cointegration and asymmetric Error Correction Model (ECM)}

Testing for a structural break using the method developed by Maki (2012) allows identifying changing coefficients in the long-term relationship between prices. Nevertheless, although we consider only one long-run equilibrium, it is also important to assess the possibility of an asymmetric adjustment towards this equilibrium. Indeed, the standard linear method assumes that the adjustment mechanism to reach equilibrium is symmetric. However, in some cases, there could be non-linearity in the relationship and, therefore, asymmetric adjustment. This point is particularly true when assessing the arbitrage dynamics between prices when transaction costs exist. This phenomenon could be tested using threshold cointegration tests and threshold error correction models (TECM). Balke and Fomby (1997) introduce a method that combines both non-linearity and cointegration to test for the presence of a threshold effect. In the empirical literature, several tests have been implemented for threshold cointegration (see Enders and Silkos, 2001; Lo and Zivot, 2001; Hansen and Seo, 2002). In this paper, we rely on the test procedure proposed by Enders and Siklos (2001). In the standard Engle and Granger (1987) two-step method, the existence of cointegration is tested using an $\mathrm{ADF}$ test on the residuals ( $\varepsilon_{t}$ ) of the equation describing the long-term relationship. However, this approach is not consistent if the adjustment mechanism is nonlinear. Therefore, Enders and Siklos (2001) propose modifying the test on the residuals to allow for non-linear adjustment as in the following:

$$
\Delta \varepsilon_{t}=I_{t} \rho_{1} \varepsilon_{t-1}+\left(1-I_{t}\right) \rho_{2} \varepsilon_{t-1}+\sum_{i=1}^{k} \gamma_{i} \Delta \varepsilon_{t-1}+u_{t}
$$

where $\rho_{1}, \rho_{2}$ and $\gamma_{i}$ are the coefficients, $k$ is the number of lags and $I_{t}$ is the Heaviside indicator function such that: 


$$
I_{t}= \begin{cases}1 & \text { if } \varepsilon_{t-1} \geq \tau \\ 0 & \text { if } \varepsilon_{t-1}<\tau\end{cases}
$$

where $\tau_{\text {is }}$ the threshold value. These two equations define the threshold autoregression (TAR) model. This model allows non-linear "deep" movements in the residuals. As an alternative adjustment process, Enders and Siklos (2001) also propose the momentum threshold (MTAR) model in which only the Heaviside function differs as in the following:

$$
I_{t}=\left\{\begin{array}{l}
1 \text { if } \Delta \varepsilon_{t-1} \geq \tau \\
0 \text { if } \Delta \varepsilon_{t-1}<\tau
\end{array}\right.
$$

In the MTAR model, the $\varepsilon_{t}$ series exhibits more "momentum" in one direction than in the other. This model is more accurate for price changes that display more momentum in one direction than in another (positive or negative).

Note that there are two approaches to determine the threshold value. The first one is to set exogenously the threshold to zero (i.e., $\tau=0$ ). The second one is to determine the value of $\tau$ endogenously by the dataset. In this case, the models are called consistent-TAR and consistent-MTAR. In this paper, we rely on the second method and set the threshold endogenously using the search method developed by Chan (1993). According to this procedure, $\varepsilon_{t-1}$ for the TAR model and $\Delta \varepsilon_{t-1}$ for the MTAR model are sorted in ascending order, and the lowest and highest $15 \%$ of the threshold values are excluded. Then, on the remaining $70 \%$ band, we consistently estimate the threshold value if given by the lowest residual sum of squares. In this paper, we want to test for asymmetric cointegration using consistent-TAR and consistent-MTAR models. The choice between the two types of model is made using the AIC and BIC information criteria as in Enders and Siklos (2001). Finally, we examine the existence of a non-linear cointegration relationship between different prices using two tests. First, the F-statistics, called $\Phi_{u}$ and $\Phi_{u^{*}}$, are used to test the null hypothesis of nocointegration $\left(\rho_{1}=\rho_{2}=0\right)$ in the TAR and MTAR models, respectively. If the hypothesis of no-cointegration is rejected, we test for the null hypothesis of symmetry $\left(\rho_{1}=\rho_{2}\right)$ using a standard F-test.

We rely on this approach to test for threshold cointegration. If threshold cointegration is confirmed by the test provided by Enders and Siklos (2001), we can estimate the following asymmetric error correction model with threshold cointegration as developed in this study:

$$
\begin{aligned}
\Delta P_{t}^{1}=\alpha+\vartheta^{+} & E C M_{t-1}^{+}+\vartheta^{-} E C M_{t-1}^{-}+\sum_{i=1}^{k} \beta_{i}^{+} \Delta P_{t-i}^{1,+}+\sum_{i=1}^{k} \beta_{i}^{-} \Delta P_{t-i}^{1,-}+\sum_{i=1}^{k} \delta_{i}^{+} \Delta P_{t-i}^{2,+} \\
& +\sum_{i=1}^{k} \delta_{i}^{-} \Delta P_{t-i}^{2,-}+\mu_{t}
\end{aligned}
$$

where $\Delta P_{t}^{1}$ and $\Delta P_{t}^{2}$ are the natural gas prices in the U.K., Asia or the U.S. in the first difference, and $\mu_{t}$ is the error term. Following Sun (2011), all of the lagged gas price 
variables in the first difference are split into positive and negative components (superscripts + or - in the equation). For example, $\Delta P_{t-1}^{1,-}=P_{t-1}^{1}-P_{t-2}^{1}$ if $P_{t-1}^{1}<P_{t-2}^{1}$, and 0 otherwise. Note that the optimal lag value $(\mathrm{k})$ is chosen according to the minimum value of the BIC and according to the Ljung-Box $\mathrm{Q}_{\text {test }}$ to have no serial autocorrelation in the residuals. Finally, the error correction term (ECM) is constructed according to the value of the threshold and using the Heaviside function ${ }^{14}$. Note that one of the main drawbacks of this approach is that it only allows one threshold. However, it could be sufficient to assess the existence of market arbitrage between natural gas prices.

It should be noted that the existence of explosive behaviour in price dynamics and heteroscedasticity affect the size of unit root and cointegration tests and can therefore bias the long-term relationships results. A robustness check using weekly data is therefore imperative to ensure that results are valid. Thus, we first test our weekly time series for explosive behaviour using the recursive test procedure proposed by Phillips, Shi, and Yu (2015), which has proved to be more robust than the Phillips, Wu and $\mathrm{Yu}$ (2011) test in the presence of multiple explosive episodes. Second, as the PSY test allows us to reject the hypothesis of an explosive behaviour at the $5 \%$ level for most of the studied prices ${ }^{15}$, we apply all unit root and cointegration tests to our weekly data. The results are consistent with the ones using daily data $^{16}$.

\section{Results}

\subsection{Time series properties of prices}

As discussed in the previous part, we initially investigate the existence of structural changes in the deterministic components of our data using the test proposed by Perron and Yabu $(2009)^{17}$. Table 2 reports the test statistic Exp- $\mathrm{W}_{\mathrm{RQF}}$ and the date of the structural break detected for each price.

The null hypothesis of absence of a structural break in both the level and slope of the time trend is rejected for series under scrutiny in our study, suggesting that there is at least one structural change in each price series. This break occurs in 11/2010 for ZEE, NBP and PEG North, in 2012 for PEG South, CEGH, TTF, NCG, Gaspool, and JKM, in 2008 for Henry Hub and Coal and in 2013 for oil. Therefore, it is important to account for possible breaks when investigating the stationarity of our variable, and standard unit root tests, suggesting that all prices are integrated of order one, loose their explanatory power ${ }^{18}$.

\footnotetext{
${ }^{14}$ For the analysis, we rely on the R-package APT written by Changyou Sun (2011).

${ }^{15}$ See Table A.3. in the Appendix.

${ }^{16}$ The results of these tests are available in the online Appendix.

${ }^{17}$ We use the GAUSS code kindly provided by Pierre Perron (http://people.bu.edu/perron/code.html).

${ }^{18}$ See Table A.1. in the Appendix for results concerning standard unit root tests.
} 
Table 2. Perron-Yabu test for structural changes in the deterministic components

\begin{tabular}{lccccc}
\hline & Exp- W-RQF & Break date & $\mathrm{cv}(1 \%)$ & $\mathrm{cv}(5 \%)$ & $\mathrm{cv}(10 \%)$ \\
\hline Panel A: Gas prices & & & & & \\
Belgium (ZEE) & 194.683 & $24 / 11 / 2010$ & 4.47 & 3.12 & 2.48 \\
U.K. (NBP) & 139.704 & $22 / 11 / 2010$ & 4.47 & 3.12 & 2.48 \\
France (PEG South) & 28.286 & $01 / 10 / 2012$ & 4.48 & 3.13 & 2.49 \\
France (PEG North) & 54.407 & $22 / 11 / 2010$ & 4.48 & 3.13 & 2.49 \\
Austria (CEGH) & 130.766 & $03 / 04 / 2012$ & 4.48 & 3.13 & 2.49 \\
Netherlands (TTF) & 397.085 & $26 / 08 / 2012$ & 4.48 & 3.13 & 2.49 \\
Germany (Gaspool) & 389.331 & $03 / 09 / 2012$ & 4.48 & 3.13 & 2.49 \\
Germany (NCG) & 69.432 & $03 / 05 / 2010$ & 4.48 & 3.13 & 2.49 \\
U.S. (Henry Hub) & 40.186 & $11 / 12 / 2008$ & 4.48 & 3.13 & 2.49 \\
Japan-Korean (JKM) & 27.221 & $04 / 06 / 2012$ & 4.48 & 3.13 & 2.49 \\
Panel B: Oil and Coal & & & & & \\
Oil & 116.286 & $05 / 05 / 2013$ & 4.48 & 3.13 & 2.49 \\
Coal & 19.719 & $10 / 10 / 2008$ & 4.48 & 3.13 & 2.49 \\
\hline
\end{tabular}

Note: Trimmer parameter is equal to 0.15. The critical values are taken Table 2c of Perron and Yabu (2009).

Table 3 provides results of the GLS-based unit root test from Carrion-i-Silvestre et al. $(2009)^{19}$.

Table 3. Results of Carrion-i-Silvestre et al. (2009) unit root tests with structural breaks

\begin{tabular}{lcccccc}
\hline & $P_{T}^{G L S}$ & $M P_{T}^{G L S}$ & $M Z_{\alpha}^{G L S}$ & $M S B^{G L S}$ & $M Z_{t}^{G L S}$ & Numbers of breaks \\
\hline Austria (CEGH) & 13.91 & 12.88 & -29.42 & 0.129 & -3.90 & 4 \\
& {$[6.77]$} & {$[6.77]$} & {$[-51.10]$} & {$[0.098]$} & {$[-5.03]$} & \\
Belgium (ZEE) & 10.34 & 8.32 & -42.21 & 0.108 & -4.59 & 4 \\
& {$[6.91]$} & {$[6.91]$} & {$[-48.30]$} & {$[0.101]$} & {$[-4.86]$} & \\
Netherlands (TTF) & 9.03 & 7.602 & -45.39 & 0.105 & 4.76 & 4 \\
& {$[6.54]$} & {$[6.54]$} & {$[-50.32]$} & {$[0.099]$} & {$[-4.99]$} & \\
U.K. (NBP) & 10.02 & 7.86 & -44.63 & 0.105 & -4.72 & 4 \\
France (PEG North) & {$[6.59]$} & {$[6.59]$} & {$[-50.48]$} & {$[0.099]$} & {$[-5.01]$} & \\
& 12.04 & 11.06 & -24.58 & 0.142 & -3.51 & 3 \\
France (PEG South) & {$[5.90]$} & {$[5.90]$} & {$[-44.59]$} & {$[0.105]$} & {$[-4.70]$} & \\
& 5.68 & 5.58 & -29.768 & 0.129 & -3.85 & 4 \\
Japan-Korean (JKM) & {$[5.56]$} & {$[5.56]$} & {$[-28.34]$} & {$[0.126]$} & {$[-3.79]$} & \\
& 19.51 & 18.53 & -20.05 & 0.157 & -3.16 & 4 \\
U.S. (Henry Hub) & {$[6.99]$} & {$[6.99]$} & {$[-50.13]$} & {$[0.099]$} & {$[-4.99]$} & \\
& 13.39 & 11.11 & -33.82 & 0.121 & -4.11 & 4 \\
Germany (Gaspool) & {$[6.80]$} & {$[6.80]$} & {$[-51.05]$} & {$[0.099]$} & {$[-5.05]$} & \\
& 10.141 & 9.288 & -37.13 & 0.115 & -4.304 & 4 \\
Germany (NCG) & {$[6.49]$} & {$[6.49]$} & {$[-50.43]$} & {$[0.099]$} & {$[-5.00]$} & \\
Oil (Index) & 10.02 & 9.74 & -16.87 & 0.171 & -2.89 & 1 \\
& {$[5.21]$} & {$[5.21]$} & {$[-30.17]$} & {$[0.126]$} & {$[-3.89]$} & \\
Coal & 251.70 & 237.31 & -1.07 & 0.496 & -0.53 & 5
\end{tabular}

19 We use the GAUSS code kindly provided to us by Josep Lluis Carrion-i-Silvestre (http://www.eco.ub.es/ carrion/Welcome.html). 
$[6.75] \quad[6.75] \quad[-48.78] \quad[0.101] \quad[-4.92]$

Note: Critical values for the $1 \%$ level significance are in brackets. The test is implemented for model III, where the structural break affects both the level and the slope of the time trend. $P_{T}^{G L S}$ is the feasible point optimal test, $M P_{T}^{G L S}$ is the modified point optimal test, $M Z_{\alpha}^{G L S}$ is the modified Phillips-Perron $M Z_{\alpha}$ test, $M S B^{G L S}$ is the modified Sargan-Bhargava test, and $M Z_{t}^{G L S}$ is the modified Phillips-Perron $M Z_{t}$ test.

It reveals that all of the price series under scrutiny are non-stationary. Indeed, the null hypothesis of the presence of a unit root with $m$ structure cannot be rejected for each variable at the $1 \%$ level. Nevertheless, the null hypothesis is rejected at the $1 \%$ level for the first difference of our variables, suggesting that they are integrated of order one (I(1)), as shown in previous studies (Siliverstos et al., 2005; Ramberg and Parsons, 2015).

\subsection{Structural breaks and cointegration tests}

Table 4 reports the results of the more general formulation of the Gregory-Hansen test, which allows a regime shift in which intercept, slope coefficients and trend change (Model 4). Panel A displays results concerning the cointegration between European gas prices and $\mathrm{HH}$. According to both $\mathrm{Z}_{\mathrm{t}}$ and $\mathrm{Z}_{\mathrm{a}}$ statistic tests, the null hypothesis of no cointegration is rejected at the 5\% level in all bivariate tests, with the exception of CEGH and $\mathrm{HH}$. Two closely related reasons can be considered to explain this latter result of no cointegration between the CEGH and the HH. First, most of the hubs considered in this study are located in Northern or Western Europe. The CEGH is, on the other hand, positioned in Central Europe, which gives it a particular role, directly or indirectly influenced by the reality of gas flows between Russia, Ukraine and Europe. The manifold tensions that have plagued Russian-Ukrainian relations over the past ten years have resulted in temporary suspensions of Russian gas supplies to Ukraine and, as a result, a temporary change in European gas flows, traditionally oriented from east to west. Secondly, and as Petrovski (2015) points out, physical bottlenecks at Oberkappel (Austria), the interconnection point between the German MEGAL pipeline and the bi-directional WAG pipeline, may explain the disconnection between CEGH and NCG prices in Germany and therefore, in our study, with those of the HH.

Results are very similar for the JKM since the null hypothesis of no cointegration between Asian and American prices cannot be rejected over the period studied. Consequently, it is reasonable to assume that there has been no cointegration between the JKM and Henry Hub since 2009. Conversely, we note that there is a cointegration relationship between European prices and $\mathrm{HH}$, but it exhibits a structural break. This break could be interpreted as the verification of one of the first conditions for demonstrating the integration of these two regional areas. However, this statement should be qualified inasmuch as different causes can be conducive to the same outcome, i.e., a common dependence upon oil prices. In reality, as highlighted by Neumann (2009), Ritz (2014) and Oglend et al. (2015), this result testifies to the fact that U.S. gas markets have profoundly changed with the shale gas boom. 


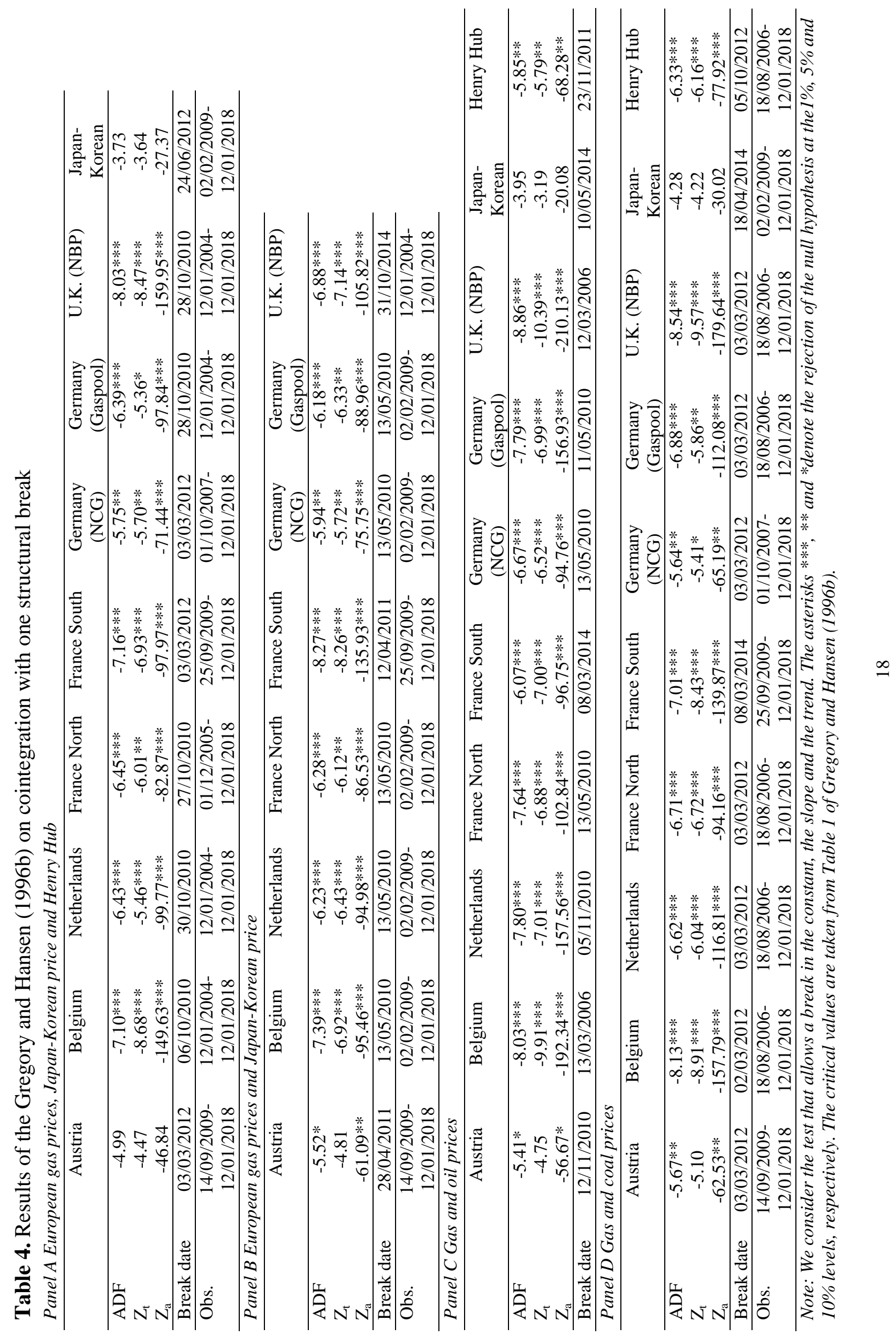


Prior to this "revolution", the integration between gas and oil prices was enabled by substitution possibilities between oil and gas. In the European case, the prevalence of oilindexed long-term contracts ensured the existence of a long-term relationship. Due to the shale gas revolution, the growth in the U.S. gas supply outpaced the increase in demand. Combined with low LNG export capabilities, this increase led to a surge in inventory levels and pushed gas prices off a cliff, whereas they did not fall so precipitously in other parts of the world. Furthermore, we shed light on the fact that the different breaks detected in the relationship between European and American gas prices appear to coincide. Indeed, for five European gas prices, the break date in the cointegration relationship is identified in October 2010. Consistent with Asche et al. (2013), this result provides further evidence of integration of the European market because the break date is identical among almost all European prices and the Henry Hub. A cointegration relationship with a structural break is also confirmed for all European prices with the Japan-Korean Marker. The structural break appears to occur around May 2010 for almost all European prices. However, these results must be interpreted in light of the cointegration relationship between natural gas and oil prices. For the latter, we indeed reject the null hypothesis of no cointegration in almost all cases. Thus, the cointegration relationship between natural gas and oil prices displays a structural change over the period considered. For almost all European gas prices, the break date occurs in 2010, confirming that the relationship between natural gas and oil prices evolves through time and appears to be nonlinear as suggested in particular by Asche et al. (2017). Only the JKM appears not to be cointegrated with oil in the period 2009-2018. Finally, we also find that all natural gas prices are cointegrated (with a structural break) with coal prices with the exception of the CEGH. Here, the break for European prices is the same for almost all prices, suggesting that European prices share a common stochastic trend, and is detected for May 2010. For the $\mathrm{HH}$, the break is found in March $2006^{20}$. Not surprisingly, Table A.2. highlights that all European gas prices are co-integrated around a structural break.

We then use Maki's (2012) ${ }^{21}$ approach to test for more than one break in the cointegration relationship between European gas prices, Henry Hub, the JKM, oil and coal prices. Results of Maki's (2012) cointegration test are demonstrated in Table 5.

The results imply that the null hypothesis of no cointegration between almost all European prices and Henry Hub can be rejected at the 5\% level, with the exceptions being CEGH and French PEG-North. The test reveals that three structural shifts are detected in the cointegration relationships. The same results are found for natural gas and oil prices, with the exception of the JKM, confirming our previous conclusion that the JKM is not cointegrated with oil, even when multiple breaks are allowed in the cointegration test.

\footnotetext{
${ }^{20}$ Because this work is not dedicated, as such, to the analysis of the link between natural gas prices and other energy sources, we do not investigate further the significance of this break date.

${ }^{21} \mathrm{We}$ are very grateful to Daiki Maki for providing us the GAUSS code to implement cointegration tests.
} 
Table 5. Maki's (2012) bivariate cointegration tests results

\begin{tabular}{|c|c|c|c|}
\hline \multicolumn{4}{|c|}{ European gas prices and JKM with U.S. Henry Hub } \\
\hline & Statistics & Critical value & Break dates \\
\hline Belgium (ZEE) & $-6.971 * *$ & -6.524 & 03/10/2006; 07/11/2008; 03/06/2014 \\
\hline U.K. (NBP) & $-6.600 * *$ & -6.524 & 20/03/2006; 07/11/2008; 20/06/2013 \\
\hline Netherlands (TTF) & $-6.775 * *$ & -6.524 & 03/10/2006; 10/11/2008; 03/06/2014 \\
\hline Germany (Gaspool) & $-6.877 * *$ & -6.524 & 03/10/2006; 10/11/2008; 30/10/2014 \\
\hline Germany (NCG) & $-7.294 * * *$ & -6.524 & $20 / 03 / 2009 ; 16 / 12 / 2012 ; 04 / 06 / 2014$ \\
\hline Japan-Korean & -5.785 & -6.524 & \\
\hline Austria $(\mathrm{CEGH})$ & -5.250 & -6.524 & \\
\hline France (PEG South) & $-7.619 * * *$ & -6.524 & $09 / 12 / 2012 ; 20 / 02 / 2014 ; 10 / 01 / 2016$ \\
\hline France (PEG North) & -4.820 & -6.524 & \\
\hline \multicolumn{4}{|c|}{ Gas prices with oil } \\
\hline Belgium (ZEE) & $-8.455 * * *$ & -6.524 & 20/03/2006; 31/12/2009; 28/03/2013 \\
\hline U.K. (NBP) & $-8.138 * * *$ & -6.524 & 20/03/2006; 31/12/2009; 20/06/2013 \\
\hline Netherlands (TTF) & $-7.514 * * *$ & -6.524 & 03/10/2006; 10/11/2008; 22/05/2014 \\
\hline Germany (Gaspool) & $-7.646 * * *$ & -6.524 & 03/10/2006; 10/11/2008; 22/05/2014 \\
\hline Germany (NCG) & $-6.600 * *$ & -6.524 & 06/10/2009; 07/02/2012; 31/10/2013 \\
\hline Japan-Korean & -5.547 & -6.524 & \\
\hline Austria (CEGH) & -5.324 & -6.524 & \\
\hline France (PEG South) & $-7.205^{* *}$ & -6.524 & $02 / 10 / 2011 ; 12 / 04 / 2013 ; 24 / 10 / 2014$ \\
\hline France (PEG North) & $-7.467 * * *$ & -6.524 & 11/03/2008; 08/12/2009; 07/02/2012 \\
\hline United States $(\mathrm{HH})$ & $-5.586 * *$ & -5.541 & $28 / 09 / 2009$ \\
\hline \multicolumn{4}{|c|}{ European gas prices with Japan Korean (JKM) } \\
\hline Belgium (ZEE) & $-6.808 * * *$ & -6.100 & 05/07/2010; 29/03/2013 \\
\hline U.K. (NBP) & $-5.877 *$ & -6.100 & $21 / 06 / 2013 ; 13 / 11 / 2015$ \\
\hline Netherlands (TTF) & $-6.781 * * *$ & -6.100 & $30 / 09 / 2001 ; 29 / 03 / 2013$ \\
\hline Germany (Gaspool) & $-5.821 * * *$ & -5.541 & $13 / 05 / 2010$ \\
\hline Germany (NCG) & $-6.303 * *$ & -6.100 & $29 / 03 / 2013 ; 03 / 04 / 2016$ \\
\hline Austria (CEGH) & -5.239 & -6.100 & \\
\hline France (PEG South) & $-8.533 * * *$ & -6.100 & $02 / 10 / 2011 ; 12 / 04 / 2013$ \\
\hline France (PEG North) & $-6.781 * * *$ & -6.100 & 08/06/2010; 10/04/2013 \\
\hline
\end{tabular}

Note: Critical values at the 0.05 significance level are from Table 1 of Maki (2012). *,**,*** denotes the rejection of the null hypothesis of no cointegration. Break dates are obtained by using Maki's (2012) cointegration test.

\subsection{Long-term estimates}

Because the presence of cointegration between natural gas and oil prices has been demonstrated, we can estimate the long-term relationship between all pairs of prices. We employ the Dynamic Ordinary Least Squares (DOLS) approach to estimate all long-term relationships:

$$
P_{t}^{1}=\alpha+\beta P_{t}^{2}+\varepsilon_{t}
$$

Note that we allow for the presence of a trend in the long-term relationship, as tested previously using the Gregory and Hansen (1996b) and Maki (2012) cointegration tests. 
Tables 6 and 7 report the long-term estimates (Eq. 5), including the test for the LOP that tests the hypothesis that the slope coefficient is equal to one for the pre- and post-structural break periods specific to each pair of prices and detected in Gregory and Hansen (1996b) and Maki's (2012) cointegration tests. Table 6 focusses on the European gas market, and Table 8 emphasizes results for European, U.S. and oil prices.

Table 6. Estimation of long-term coefficients (DOLS, Bartlett Kernel, Newey-West fixed bandwidth)- European natural gas market

\begin{tabular}{|c|c|c|c|c|c|c|}
\hline & \multicolumn{3}{|c|}{ With U.K. NBP } & \multicolumn{3}{|c|}{ With Netherlands TTF } \\
\hline & First period & $\begin{array}{c}\text { Second } \\
\text { period }\end{array}$ & Break date & First period & $\begin{array}{l}\text { Second } \\
\text { period }\end{array}$ & Break date \\
\hline Austria (CEGH) & $\begin{array}{c}0.852 * * * \\
(0.020)\end{array}$ & $\begin{array}{c}0.564 * * * \\
(0.033)\end{array}$ & $28 / 05 / 2016$ & $\begin{array}{c}0.842 * * * \\
(0.018)\end{array}$ & $\begin{array}{c}0.908 * * * \\
(0.013)\end{array}$ & 06/02:2015 \\
\hline$L O P$ & $51.35 * * *$ & $177.27 * * *$ & & $74.45 * * *$ & $49.36 * *$ & \\
\hline Belgium (ZEE) & $\begin{array}{c}0.852 * * * \\
(0.041)\end{array}$ & $\begin{array}{c}0.987 * * * \\
(0.006)\end{array}$ & $23 / 06 / 2006$ & $\begin{array}{c}1.695 * * * \\
(0.087)\end{array}$ & $\begin{array}{c}1.020 * * * \\
(0.006)\end{array}$ & $15 / 12 / 2006$ \\
\hline$L O P$ & $13.05 * * *$ & $3.94 * *$ & & $63.56^{* * *}$ & $10.80 * * *$ & \\
\hline Netherlands (TTF) & $\begin{array}{c}0.441 * * * \\
(0.048)\end{array}$ & $\begin{array}{c}0.960 * * * \\
(0.009)\end{array}$ & 04/10/2006 & & & \\
\hline$L O P$ & $135.12 * * *$ & $17.79 * * *$ & & & & \\
\hline Germany (Gaspool) & $\begin{array}{c}0.429 * * * \\
(0.047)\end{array}$ & $\begin{array}{c}0.945 * * * \\
(0.010)\end{array}$ & 04/10/2006 & $\begin{array}{c}0.985 * * * \\
(0.002)\end{array}$ & $\begin{array}{c}0.987 * * * \\
(0.004)\end{array}$ & $22 / 04 / 2008$ \\
\hline$L O P$ & $143.84 * * *$ & $28.82 * * *$ & & $42.61 * * *$ & $10.14 * * *$ & \\
\hline Germany (NCG) & $\begin{array}{c}1.018 * * * \\
(0.021)\end{array}$ & $\begin{array}{c}0.960 * * * \\
(0.012)\end{array}$ & $05 / 11 / 2009$ & $\begin{array}{c}0.920 * * * \\
(0.016)\end{array}$ & $\begin{array}{c}0.975 * * * \\
(0.004)\end{array}$ & $31 / 03 / 2009$ \\
\hline$L O P$ & 0.743 & $9.65 * * *$ & & $22.86 * * *$ & $32.22 * * *$ & \\
\hline France (PEG North) & $\begin{array}{c}0.826 * * * \\
(0.022)\end{array}$ & $\begin{array}{c}0.957 * * * \\
(0.010)\end{array}$ & $28 / 04 / 2008$ & $\begin{array}{c}0.535 * * \\
(0.219)\end{array}$ & $\begin{array}{c}0.993 * * * \\
(0.005)\end{array}$ & $07 / 09 / 2006$ \\
\hline$L O P$ & $59.53 * * *$ & $19.14 * * *$ & & $4.47 * *$ & 1.945 & \\
\hline France (PEG South) & $\begin{array}{c}0.838 * * * \\
(0.023)\end{array}$ & $\begin{array}{c}0.968 * * * \\
(0.077)\end{array}$ & $24 / 10 / 2014$ & $\begin{array}{c}0.868 * * * \\
(0.019)\end{array}$ & $\begin{array}{c}1.010 * * * \\
(0.060)\end{array}$ & $21 / 10 / 2014$ \\
\hline$L O P$ & $47.47 * * *$ & 0.167 & & $46.36 * * *$ & 0.044 & \\
\hline
\end{tabular}

Unsurprisingly, our results show that most of the European gas markets considered in this study have become integrated in recent years, with the CEGH being the exception for the reasons mentioned above. The structural break tests clearly show that 2006 was a pivotal year in this regard for the Belgian, Dutch and German (Gaspool) markets. However, this statement does not apply to all European markets, due in particular to differences in the timeframes of the price series considered here. The estimated cointegrating vectors between these prices (except CEGH) thus range between $(1,-0.9)$ and $(1,-1.02)$ in the second periods of the study. Furthermore, the LOP is accepted between PEG South and NBP, and between PEG South and PEG North and TTF. This result complements the previous analysis of Renou-Maissant (2012) which is based on industrial prices to end-users, using more European prices and for a more recent period. Although there are exceptions, it appears that there is a strong integration of natural gas markets in continental Europe, particularly between France South, Netherlands and Germany (Gaspool). In contrast to Renou-Maissant (2012) however, we find that the Belgian market is integrated with some other continental markets, even including the U.K. 
Furthermore, it appears that almost all continental markets are integrated with the NBP, showing what might be interpreted as an increasing convergence process between continental countries and the U.K since the study of Renou-Maissant (2012). Beyond this simple fact, however, much can be said of the nature of this convergence process. The NBP and the TTF (to a lesser extent) have been the most liquid gas hubs in Europe because of the comprehensive liberalization process through which they have been. Hence, one can ask whether this higher degree of price interdependence is the result of an increased reliance in Europe on NBP and TTF as reference market prices or, conversely, the consequence of a deepening of gas continental European markets as a premise of the single European market wanted by regulatory authorities.

If we investigate the integration between the European and the U.S. gas markets, the picture appears to be quite different (Table 7). First, all of the Wald tests reveal that the hypothesis of perfect market integration between Europe and the U.S., and between Europe and JapanKorea is rejected at the $1 \%$ level. This result remains valid in post- and pre-break periods. Unsurprisingly, this point demonstrates that even with the development of LNG and fall in transportation costs, there remains no perfect integration of the natural gas market.

As suggested in the introduction, the rise of the American LNG could encourage this integration. However, the first U.S. LNG exports began in 2016; thus, it remains too early to measure their effects. This point is even truer given that cost logic must naturally be considered and that, from this point of view, American LNG remains on average more expensive than land-based gas delivered to Europe. However, results suggest that the degree of integration between Europe and the U.S. has increased, particularly in the last period of study (since May 2014). Indeed, the long-term coefficient has recorded shifts over the whole period as revealed by cointegration tests. Until 2006 (first period), European and U.S. gas prices appears to co-evolve, and on average, this coefficient was approximately 0.5 . Nevertheless, this coefficient is not significant for NBP and Gaspool in this first period (2004-2006). For all European prices, with the exception of NBP, the long-term coefficient is small until 2014, suggesting a weak integration of markets. However, after 2014 (fourth period), the cointegrating vector is high, and the long-term coefficient is on average 0.65 , revealing a higher degree of integration between European and U.S. gas markets. This point is particularly true for German Gaspool, with a long-term coefficient of 0.876 for the period October 2014-January 2018.

Conclusions concerning co-movements between European and Japan-Korean prices are different. Indeed, our results reveal a strong cointegrating vector in the first period, i.e., between February 2009 and September 2011, for TTF, for instance, followed by a period of decoupling of almost all European prices and the JKM. Then, in the last period, i.e., since March 2013 for almost all prices, the cointegrating vector is again important and on average approximately 0.5 .

If we analyse these results in the light of co-movements between natural gas and oil prices, new insights appear (Table 7). 


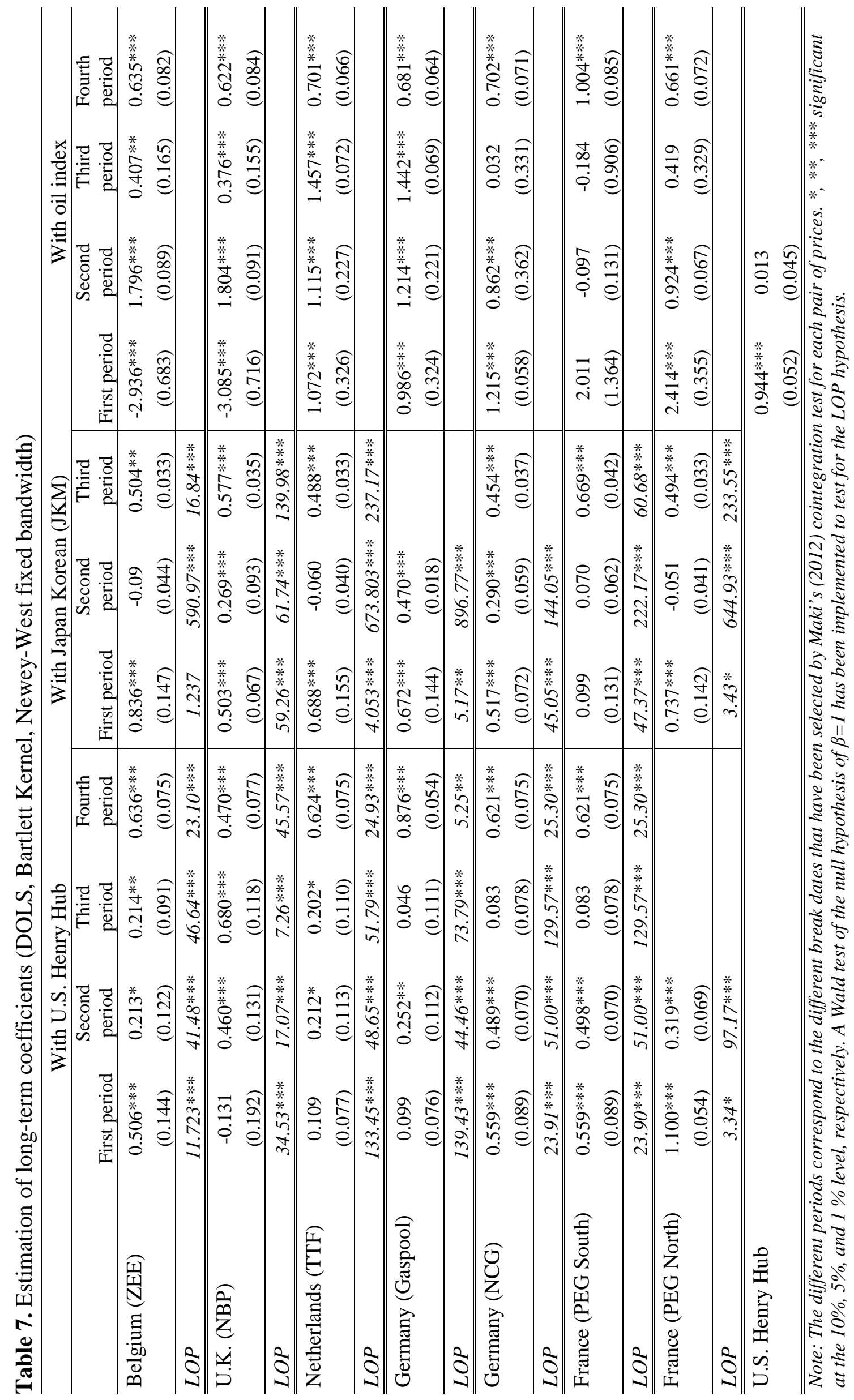


Indeed, results in Table 7 highlight a less intense long-term relationship between some natural gas and oil prices in the last period, i.e. since May 2014 (TTF and Gaspool), and in the third period, i.e. since December 2009 (ZEE and NBP). Overall, it seems that the long-run relationship between gas and oil prices is less intense in the last two periods that in the first two periods. On the one hand, we find a stronger cointegrating vector between European and U.S. gas prices on average. On the other hand, we find a lower cointegrating vector between European gas and oil prices. The association of these two phenomena is, in our view, indicative of the deep transformation of the market towards greater integration or, at the very least, of an increase in physical arbitrage strategies.

\subsection{Threshold cointegration and asymmetric ECM}

Table 8 reports the results of the asymmetric cointegration test proposed by Enders and Siklos (2001), which tests the null hypothesis of no cointegration against the alternative of threshold cointegration (Eq. 3). Notice that we present only results for the consistent-MTAR (or TAR) models selected according to the minimum value of AIC and BIC.

Table 8. Threshold cointegration tests for natural gas (Enders and Siklos, 2001)

\begin{tabular}{|c|c|c|c|c|c|c|}
\hline & $\begin{array}{l}\text { NBP and } \\
\text { Henry Hub }\end{array}$ & $\begin{array}{c}\text { Henry Hub } \\
\text { and JKM }\end{array}$ & $\begin{array}{l}\text { TTF and } \\
\text { Henry Hub }\end{array}$ & $\begin{array}{l}\text { NBP and } \\
\text { TTF }\end{array}$ & $\begin{array}{l}\text { NBP and } \\
\text { JKM }\end{array}$ & $\begin{array}{l}\text { TTF and } \\
\text { JKM }\end{array}$ \\
\hline Model & $\begin{array}{l}\text { Consistent } \\
\text { MTAR }\end{array}$ & $\begin{array}{l}\text { Consistent } \\
\text { TAR }\end{array}$ & $\begin{array}{l}\text { Consistent } \\
\text { MTAR }\end{array}$ & $\begin{array}{c}\text { Consistent } \\
\text { MTAR }\end{array}$ & $\begin{array}{l}\text { Consistent } \\
\text { MTAR }\end{array}$ & $\begin{array}{c}\text { Consistent } \\
\text { MTAR }\end{array}$ \\
\hline Lag & 2 & 1 & 2 & 2 & 2 & 2 \\
\hline Threshold & 0.032 & -0.143 & 0.027 & -0.021 & -0.005 & -0.004 \\
\hline$\rho_{1}$ & $\begin{array}{c}-0.054 * * * \\
(-8.667)\end{array}$ & $\begin{array}{c}-0.015 * * * \\
(-3.872)\end{array}$ & $\begin{array}{c}-0.026 * * * \\
(-4.080)\end{array}$ & $\begin{array}{c}-0.059 * * * \\
(-6.590)\end{array}$ & $\begin{array}{c}-0.022 * * * \\
(-3.590)\end{array}$ & $\begin{array}{c}-0.035 * * * \\
(-6.242)\end{array}$ \\
\hline$\rho_{2}$ & $\begin{array}{l}-0.006^{*} \\
(-1.793) \\
\end{array}$ & $\begin{array}{c}-0.005 \\
(-1.417) \\
\end{array}$ & $\begin{array}{c}-0.009 * * * \\
(-3.060)\end{array}$ & $\begin{array}{c}-0.153^{* * * *} \\
(-12.235) \\
\end{array}$ & $\begin{array}{c}-0.041 * * * \\
(-5.376) \\
\end{array}$ & $\begin{array}{l}-0.011^{*} \\
(-1.693) \\
\end{array}$ \\
\hline AIC & -11594.04 & -13702.55 & -13283.78 & -14252.86 & -10536.16 & -11595.58 \\
\hline BIC & -11561.23 & -13678.66 & -13251.57 & -14220.64 & -10506.30 & -11595.72 \\
\hline $\mathrm{Q}_{\mathrm{LB}}(4)$ & 0.00 & 0.234 & 0.00 & 0.00 & 0.068 & 0.00 \\
\hline$\Phi: \rho_{1}=\rho_{2}=0$ & 39.070 & 8.489 & 12.992 & 92.86 & 20.945 & 20.904 \\
\hline $\begin{array}{l}\text { Critical values } \\
(10 \%)\end{array}$ & 6.47 & 6.41 & 6.47 & 6.47 & 6.47 & 6.47 \\
\hline $\begin{array}{l}\text { Critical values } \\
(5 \%)\end{array}$ & 7.53 & 7.39 & 7.53 & 7.53 & 7.53 & 7.53 \\
\hline $\begin{array}{l}\text { Critical values } \\
(1 \%)\end{array}$ & 9.76 & 9.66 & 9.76 & 9.76 & 9.76 & 9.76 \\
\hline$F: \rho_{1}=\rho_{2}$ & $47.449 * * *$ & $3.152 *$ & $5.829 * *$ & $39.828 * * *$ & $3.791 *$ & $7.967 * * *$ \\
\hline
\end{tabular}

First, the $\Phi$ statistics lead us to reject the null hypothesis of no cointegration at the 5\% level for all specifications. Furthermore, the null hypothesis of symmetric adjustment towards longterm equilibrium is rejected at the $10 \%$ level in all cases, according to the F-statistic. Thus, our results strongly suggest that for NBP and $\mathrm{HH}, \mathrm{HH}$ and the JKM, TTF and HH and TTF and the JKM, the adjustment mechanism is asymmetric (nonlinear). In contrast to our previous results, we find that U.S. and Japan-Korean markets have been co-integrated since 
2009, but the relationship is asymmetrical. Moreover, if we analyse the value and significance of $\rho_{1}$ and $\rho_{2}$, particularly interesting results can be highlighted. For instance, if we consider the relationship between NBP and $\mathrm{HH}$, we find that the estimated threshold is 0.032 and that the point estimate for the adjustment is -0.054 for positive shocks and -0.006 for negative shocks. This outcome reveals that positive discrepancies from long-term equilibrium arising from an increase in U.K. prices or a decrease in American prices (such that $\Delta \varepsilon_{t-1}>0.032$ ) are eliminated more quickly, at a rate of $5.4 \%$ per day. In contrast, negative deviations from longterm equilibrium resulting from decreases in the U.K. prices or increases in the $\mathrm{HH}$ take more time to be adjusted ( $0.6 \%$ per day). Consequently, there is substantially slower convergence for deviations below the threshold than for deviations above the threshold. This result is consistent with fact that the relationship between NBP and HH is highly asymmetric and that U.K. prices take more time to adjust below the threshold. We can identify a similar threshold for TTF (0.027), but the point estimate for positive shocks is only -0.026 , suggesting that TTF adjusting to $\mathrm{HH}$ requires more time than for the U.K. NBP to do so. Caution is clearly necessary when interpreting such results, but it must be acknowledged that this difference could indicate that market arbitrage opportunities are more important between NBP and HH than between TTF and HH.

Our results are different for the relationship between HH and the JKM. In spite of a higher threshold (-0.143) and although $\rho_{2}$ is not significant at the 5\% level, $\rho_{1}$ is indeed significant at the $1 \%$ level and equal to -0.015 . Thus, only deviations from long-term equilibrium resulting from an increase in American prices or a decrease in the JKM are eliminated and at a lower rate than between $\mathrm{HH}$ and NBP or between $\mathrm{HH}$ and TTF. We also find that asymmetric cointegration prevails between European prices (NBP and TTF) and the JKM. Providing at this stage of our work an undisputable economic interpretation of these econometric results appears an arduous task and would require further investigation. Intuitively, a greater role played by spot markets could however be part of the explanation. In a recent context of rather oversupplied markets in which East-Asia and, to a lesser extent, Europe were the most resilient areas, any departure from long-term equilibria in the form of a short-term increase in NBP or JKM prices might have been viewed by exporting countries as a source of profitable arbitrage. This arbitrage could in turn have led to an important flow of natural gas to these countries, contributing to greater price interdependency.

Because we have demonstrated that there is a cointegration relationship between these four natural gas prices using the methodology proposed by Enders and Siklos (2001), we can estimate the corresponding TECM (Eq. 4). Tables 9 and 10 report the results. Table 9 focuses on the analysis of European and U.S. markets, whereas Table 10 analyses the integration of European and U.S. gas markets with the Japan-Korean market. 
Table 9. Results of the asymmetric error correction model with threshold cointegration (European and U.S. markets)

\begin{tabular}{|c|c|c|c|c|c|c|}
\hline & $\begin{array}{c}\text { U.K NBP } \\
\left(\Delta P_{t}^{1}\right)\end{array}$ & $\begin{array}{c}\text { U.S. HH } \\
\left(\Delta P_{t}^{2}\right)\end{array}$ & $\begin{array}{c}\text { Netherlands } \\
\text { TTF }\left(\Delta P_{t}^{3}\right)\end{array}$ & $\begin{array}{c}\text { U.S. HH } \\
\left(\Delta P_{t}^{2}\right)\end{array}$ & $\begin{array}{c}\text { U.K NBP } \\
\left(\Delta P_{t}^{1}\right)\end{array}$ & $\begin{array}{c}\text { Netherlands } \\
\text { TTF }\left(\Delta P_{t}^{3}\right)\end{array}$ \\
\hline \multirow[t]{2}{*}{$\Delta N B P_{t-1}^{+}$} & $-0.188 * * *$ & 0.003 & & & $-0.113 * * *$ & -0.009 \\
\hline & $(0.023)$ & $(0.008)$ & & & $(0.028)$ & $(0.023)$ \\
\hline \multirow[t]{2}{*}{$\Delta N B P_{t-2}^{+}$} & -0.020 & -0.004 & & & $-0.050 *$ & $0.071 * * *$ \\
\hline & $(0.024)$ & $(0.008)$ & & & $(0.028)$ & $(0.023)$ \\
\hline \multirow[t]{2}{*}{$\Delta N B P_{t-1}^{-}$} & $0.066 * * *$ & -0.008 & & & $0.070 * *$ & $0.303 * * *$ \\
\hline & $(0.023)$ & $(0.008)$ & & & (0.029) & $(0.023)$ \\
\hline \multirow[t]{2}{*}{$\Delta N B P_{t-2}^{-}$} & $-0.252 * * *$ & $-0.024 * * *$ & & & $-0.216 * * *$ & $-0.061 * * *$ \\
\hline & $(0.022)$ & $(0.008)$ & & & $(0.028)$ & $(0.023)$ \\
\hline \multirow{2}{*}{$\Delta H H_{t-1}^{+}$} & $-0.309 * * *$ & $-0.040 *$ & $-0.308 * * *$ & $-0.043 *$ & & \\
\hline & $(0.064)$ & $(0.023)$ & $(0.053)$ & $(0.023)$ & & \\
\hline \multirow[t]{2}{*}{$\Delta H H_{t-2}^{+}$} & -0.091 & -0.002 & $-0.169 * * *$ & 0.003 & & \\
\hline & $(0.064)$ & $(0.023)$ & $(0.053)$ & $(0.023)$ & & \\
\hline \multirow[t]{2}{*}{$\Delta H H_{t-1}^{-}$} & $0.383 * * *$ & $-0.077 * * *$ & $0.353 * * *$ & $-0.070 * * *$ & & \\
\hline & $(0.073)$ & $(0.026)$ & $(0.060)$ & $(0.026)$ & & \\
\hline \multirow{2}{*}{$\Delta H H_{t-2}^{-}$} & 0.103 & $0.076^{* * *}$ & $0.306 * * *$ & $0.065^{* *}$ & & \\
\hline & $(0.073)$ & $(0.026)$ & $(0.061)$ & $(0.026)$ & & \\
\hline \multirow[t]{2}{*}{$\Delta T T F_{t-1}^{+}$} & & & $-0.286 * * *$ & 0.016 & $-0.076 * *$ & $-0.285^{* * *}$ \\
\hline & & & $(0.024)$ & $(0.010)$ & $(0.034)$ & $(0.028)$ \\
\hline \multirow{2}{*}{$\Delta T T F_{t-2}^{+}$} & & & $-0.043 * *$ & 0.005 & $0.079 * *$ & $-0.093 * * *$ \\
\hline & & & $(0.023)$ & $(0.010)$ & $(0.033)$ & $(0.028)$ \\
\hline \multirow[t]{2}{*}{$\Delta T T F_{t-1}^{-}$} & & & $-0.242 * * *$ & -0.010 & 0.018 & $-0.417 * * *$ \\
\hline & & & $(0.021)$ & $(0.009)$ & $(0.033)$ & $(0.027)$ \\
\hline \multirow[t]{2}{*}{$\Delta T T F_{t-2}^{-}$} & & & $-0.260 * * *$ & -0.002 & $-0.117 * * *$ & $-0.235^{* * *}$ \\
\hline & & & $(0.022)$ & (0.009) & $(0.033)$ & $(0.027)$ \\
\hline \multirow[t]{2}{*}{$E C M_{t-1}^{+}$} & $-0.050 * * *$ & $-0.006 * * *$ & $-0.025 * * *$ & 0.000 & 0.005 & $-0.053 * * *$ \\
\hline & $(0.006)$ & $(0.002)$ & $(0.006)$ & $(0.003)$ & $(0.012)$ & $(0.010)$ \\
\hline \multirow[t]{2}{*}{$E C M_{t-1}^{-}$} & $-0.009 * *$ & 0.000 & $-0.009 * * *$ & -0.001 & $-0.173 * * *$ & -0.006 \\
\hline & $(0.003)$ & $(0.001)$ & $(0.003)$ & $(0.001)$ & $(0.017)$ & $(0.014)$ \\
\hline \multirow[t]{2}{*}{ Intercept } & $0.007 * * *$ & 0.000 & $0.007 * * *$ & 0.000 & 0.000 & 0.000 \\
\hline & $(0.002)$ & $(0.001)$ & $(0.001)$ & $(0.001)$ & $(0.001)$ & $(0.001)$ \\
\hline
\end{tabular}

Note: Lags are chosen according to the BIC. *,**,*** denote significance at the 10\%, 5\%, and 1\% levels, respectively.

Our results confirm not only that there is a long-term relationship between NBP and HH but also that the adjustment process towards long-term equilibrium is highly asymmetric. Furthermore, we find that $\left|\vartheta^{+}\right|>\left|\vartheta^{-}\right|$, which indicates that positive deviations from longterm equilibrium are eliminated more quickly than are negative deviations. They also confirm that the adjustment speed between NBP and HH is greater than that between TTF and HH, suggesting better arbitrage opportunities between NBP and $\mathrm{HH}$. Note that the adjustment speed is higher when NBP reacts to a variation of $\mathrm{HH}(-0.050)$ than when $\mathrm{HH}$ reacts to a variation of NBP (-0.006). Thus, European markets are more affected by variation in the U.S. market than the reverse. If we compare these results with those related to the integration of two European markets (TTF and NBP), we show that there is a higher adjustment speed both for positive and negative discrepancies for European gas prices.

Table 10 highlights the dependence of European gas prices upon the JKM. Indeed, we find a significant adjustment speed for NBP and TTF, for both negative and positive discrepancies from long-term equilibrium ( -0.038 and -0.020 for NBP, and -0.035 and -0.018 for TTF), 
although adjustment speed for the JKM to NBP or TTF is never significant. This result shed light on the fact that the JKM remains unaffected by variations of European gas prices in the short term. The same result applies to $\mathrm{HH}$, for which only positive deviations from long-term equilibrium are eliminated. However, these results also stress the fact that market arbitrage opportunities exist between European, U.S. and Japan-Korean natural gas prices.

Table 10. Results of the asymmetric error correction model with threshold cointegration (European, U.S. and Japan-Korean markets)

\begin{tabular}{|c|c|c|c|c|c|c|}
\hline & $\begin{array}{c}\text { U.K NBP } \\
\left(\Delta P_{t}^{1}\right)\end{array}$ & $\mathrm{JKM}\left(\Delta P_{t}^{3}\right)$ & $\begin{array}{c}\text { U.S. HH } \\
\left(\Delta P_{t}^{2}\right)\end{array}$ & $\mathrm{JKM}\left(\Delta P_{t}^{3}\right)$ & $\begin{array}{l}\text { Netherlands } \\
\text { TTF }\left(\Delta P_{t}^{2}\right)\end{array}$ & $\mathrm{JKM}\left(\Delta P_{t}^{1}\right)$ \\
\hline$\Delta N B P_{t-1}^{+}$ & $\begin{array}{l}-0.050 \\
(0.031)\end{array}$ & $\begin{array}{c}0.029 \\
(0.027)\end{array}$ & & & & \\
\hline$\Delta N B P_{t-2}^{+}$ & $\begin{array}{c}0.004 \\
(0.024)\end{array}$ & $\begin{array}{c}0.000 \\
(0.026)\end{array}$ & & & & \\
\hline$\Delta N B P_{t-1}^{-}$ & $\begin{array}{c}-0.071 * * \\
(0.030)\end{array}$ & $\begin{array}{l}-0.046 \\
(0.031)\end{array}$ & & & & \\
\hline$\Delta N B P_{t-2}^{-}$ & $\begin{array}{c}-0.176^{* * * *} \\
(0.029)\end{array}$ & $\begin{array}{c}0.062 * * \\
(0.032)\end{array}$ & & & & \\
\hline$\Delta J K M_{t-1}^{+}$ & $\begin{array}{l}-0.032 \\
(0.078)\end{array}$ & $\begin{array}{c}0.117 * * * \\
(0.040)\end{array}$ & $\begin{array}{c}0.184 * * * \\
(0.045)\end{array}$ & $\begin{array}{l}0.055^{*} \\
(0.028)\end{array}$ & $\begin{array}{c}0.004 \\
(0.064)\end{array}$ & $\begin{array}{c}0.039 \\
(0.028)\end{array}$ \\
\hline$\Delta J K M_{t-2}^{+}$ & $\begin{array}{l}-0.085 \\
(0.078)\end{array}$ & $\begin{array}{c}0.014 \\
(0.040)\end{array}$ & & & $\begin{array}{l}-0.123^{*} \\
(0.064)\end{array}$ & $\begin{array}{c}0.092 * * * \\
(0.028)\end{array}$ \\
\hline$\Delta J K M_{t-1}^{-}$ & $\begin{array}{c}0.233 * * * \\
(0.080)\end{array}$ & $\begin{array}{c}0.067 \\
(0.042)\end{array}$ & $\begin{array}{c}0.072 \\
(0.047)\end{array}$ & $\begin{array}{c}0.124 * * * \\
(0.029)\end{array}$ & $\begin{array}{c}0.256 * * * \\
(0.066)\end{array}$ & $\begin{array}{c}0.120 * * * \\
(0.029)\end{array}$ \\
\hline$\Delta J K M_{t-2}^{-}$ & $\begin{array}{c}0.207 * * * \\
(0.080)\end{array}$ & $\begin{array}{c}0.119 * * * \\
(0.042)\end{array}$ & & & $\begin{array}{c}0.189 * * * \\
(0.066)\end{array}$ & $\begin{array}{c}0.130 * * * \\
(0.029)\end{array}$ \\
\hline $\begin{array}{l}\Delta H H_{t-1}^{+} \\
\Delta H H_{t-2}^{+}\end{array}$ & & & $\begin{array}{l}-0.055^{*} \\
(0.029)\end{array}$ & $\begin{array}{c}0.022 \\
(0.018)\end{array}$ & & \\
\hline$\Delta H H_{t-1}^{-}$ & & & $\begin{array}{c}-0.104 * * * \\
(0.032)\end{array}$ & $\begin{array}{c}0.007 \\
(0.020)\end{array}$ & & \\
\hline$\Delta H H_{t-2}^{-}$ & & & & & & \\
\hline$\Delta T T F_{t-1}^{+}$ & & & & & $\begin{array}{c}-0.162 * * * \\
(0.031)\end{array}$ & $\begin{array}{l}-0.011 \\
(0.014)\end{array}$ \\
\hline$\Delta T T F_{t-2}^{+}$ & & & & & $\begin{array}{l}-0.057 \\
(0.032)\end{array}$ & $\begin{array}{c}0.019 \\
(0.014)\end{array}$ \\
\hline$\Delta T T F_{t-1}^{-}$ & & & & & $\begin{array}{c}0.035 \\
(0.029)\end{array}$ & $\begin{array}{c}0.021 \\
(0.013)\end{array}$ \\
\hline$\Delta T T F_{t-2}^{-}$ & & & & & $\begin{array}{c}0.034 \\
(0.030)\end{array}$ & $\begin{array}{l}-0.013 \\
(0.013)\end{array}$ \\
\hline$E C M_{t-1}^{+}$ & $\begin{array}{c}-0.020 * * * \\
(0.005)\end{array}$ & $\begin{array}{l}-0.001 \\
(0.005)\end{array}$ & $\begin{array}{c}-0.016 * * * \\
(0.004)\end{array}$ & $\begin{array}{l}-0.004 \\
(0.003)\end{array}$ & $\begin{array}{c}-0.035^{* * * *} \\
(0.006)\end{array}$ & $\begin{array}{c}0.003 \\
(0.003)\end{array}$ \\
\hline$E C M_{t-1}^{-}$ & $\begin{array}{c}-0.038^{* * *} \\
(0.010)\end{array}$ & $\begin{array}{l}-0.004 \\
(0.003)\end{array}$ & $\begin{array}{l}-0.004 \\
(0.004)\end{array}$ & $\begin{array}{c}0.004 \\
(0.003)\end{array}$ & $\begin{array}{c}-0.018 * * * \\
(0.006)\end{array}$ & $\begin{array}{c}0.004 \\
(0.003)\end{array}$ \\
\hline Intercept & $\begin{array}{c}0.000 \\
(0.001)\end{array}$ & $\begin{array}{c}0.000 \\
(0.001) \\
\end{array}$ & $\begin{array}{c}0.000 \\
(0.001)\end{array}$ & $\begin{array}{c}0.001 \\
(0.000) \\
\end{array}$ & $\begin{array}{c}0.004 * * * \\
(0.001)\end{array}$ & $\begin{array}{c}0.000 \\
(0.000)\end{array}$ \\
\hline
\end{tabular}

Note: Lags are chosen according to the BIC. *,**,*** denote significance at the $10 \%, 5 \%$, and $1 \%$ levels, respectively. 


\section{Conclusion}

Based on a fourteen-year period ending in January 2018, this paper provides new empirical evidence on the relationships between North American, European, and East Asian gas prices. Using not only cointegration tests with one or more structural breaks but also threshold cointegration tests and threshold error-correction models, we highlight several interesting findings and make a useful contribution to the literature on gas market integration from this perspective. In particular, we show that the integration of gas markets has increased in recent years in the sense that long-term relationships between gas prices have, for most of them, strengthened while those between gas prices and oil prices have weakened. Although our results confirm that there is a very strong integration among most of the European gas markets, but clearly no perfect integration between the European and American markets, we do indeed point out that the degree of integration between these two regions has increased, especially after 2014. Concerning Asia, we show that most European markets are, for the most part, cointegrated with the JKM while the latter is not with the HH, when the Gregory and Hansen (1996b) test is used. The increase in the cointegrating vector between U.S. and European gas prices would not have allowed us to conclude that international gas market is getting more and more integrated if it had not been accompanied by a decrease in the cointegrating vector between gas prices and oil. We demonstrate that this is the case. Testing for threshold cointegration, we also reach an interesting result on the existence of an asymmetric adjustment to long-term equilibrium between HH and NBP, but also between HH and the JKM, any positive discrepancies from long-term equilibriums in the form of an increase in the NBP or JKM price requiring a greater time to adjust than negative ones. We suggest that market arbitrages from exporting countries resulting from a growing share of spot transactions could be one of the possible explanations for such an asymmetric convergence.

These various results make this article a useful contribution to the literature on gas market integration, but our approach is not without limitations. Several suggestions about future research that might enrich this paper should therefore be mentioned as concluding remarks. First, considering that European gas hubs play different roles, greater scrutiny should be placed on the causality relationships among European prices to determine whether there is any "dominance effect" of some hubs over the others and to check whether what appears from our results to be an integrated European gas market is not a "trompe l'oeil". Second, further investigation would obviously be required to apprehend the effect of soaring LNG export capacities from the United States, which are expected to be at full capacity in 2018, on the integration of world natural gas markets. Finally, a greater focus should be placed on the asymmetric nature of the reversion to long-term equilibrium between gas prices.

\section{Bibliography}

Asche F., Oglend A. and Osmundsen, P. (2017), "Modelling UK Natural Gas Prices when Gas Prices Periodically Decouple from the Oil Price”, The Energy Journal, 38(2): 131-148.

Asche F., Minsund B. and Mikveland, M. (2013), "The relationship between spot and contract gas prices in Europe", Energy Economics, 38: 212-217. 
Asche F., Osmundsen, P. and Tveteras, R. (2002), "European market integration for gas? Volume flexibility and political risk", Energy Economics, 24: 249-265.

Balke, N. and Fomby, T. (1997) "Threshold cointegration", International Economic Review, 383: 627-645.

Barnes, R., and Bosworth, R. (2015), "LNG Is Linking Regional Natural Gas Markets: Evidence from the Gravity Model”, Energy Economics, 47: 11-17.

Brigida, M. (2014), "The switching relationship between natural gas and crude oil prices", Energy Economics, 43: 48-55.

Brown, S.P.A. and Yücel, M.K. (2009), "Market arbitrage: European and North American natural gas prices", The Energy Journal, 30: 167-186.

Carrion-i-Silvestre, J.L., Kim, D. and Perron, P. (2009), "GLS-based unit root tests with multiple structural breaks under both the null and the alternative hypotheses", Econometric Theory, 25: 1754-1792.

Chan, K.S. (1993), "Consistency and limiting distribution of the least squares estimator of a threshold autoregressive model", The Annals of Statistics, 211: 520-533.

Chan, K.-S., Hansen, B.E. and Timmermann, A. (2017), "Guest editors introduction: Regime switching and threshold models, Journal of Business \& Economic Statistics, 35(2): 159-161.

Elliot, G., Rothenberg, T.J. and Stock, J.H. (1996), "Efficient tests for an autoregressive unit root", Econometrica, 64: 813-836.

Enders, W., Siklos, P.L. (2001) "Cointegration and threshold adjustment", Journal of Business and Economic Statistics, 192: 166-176.

Engle, R.F., and Granger, C.W.J. (1987), "Cointegration and error-correction: Representation, estimation and testing", Econometrica, 55(2): 251-276.

Gregory, A.W., and Hansen, B.E. (1996a), "Residual-based tests for cointegration in models with regime shifts" Journal of Econometrics, 70: 99-126.

Gregory, A.W., and Hansen, B.E. (1996b), "Tests for cointegration in models with regime and trend shifts," Oxford Bulletin of Economics and Statistics, 58: 555-560.

Hansen, B.E. and Seo, B. (2002), "Testing for two-regime threshold cointegration in vector error-correction models", Journal of Econometrics, 110: 293-318.

Hartley, P., Medlock, K. and Rosthal, J.E. (2008), "The relationship of natural gas to oil prices", The Energy Journal, 29(3): 47-66.

Hatemi-J, A. (2008), "Tests for cointegration with two unknown regime shifts with an application to financial market integration”, Empirical Economics, 35(3): 497-505.

Heather P. (2012), "Continental European gas Hubs: are they fit for the purpose?", OIES papers, NG 62., Oxford Institute For Energy Studies. 
Heather P. (2015), "The evolution of European traded gas hubs", OIES paper, n ${ }^{\circ}$ G 104 , Oxford Institute For Energy Studies.

Hirschhausen C-V. and Neumann, A. (2008), "Long-term contracts and asset specificity revisited: an empirical analysis of producer-importer relations in the natural gas industry", Review of Industrial Organization, 32(2): 131-43.

International Energy Agency (2017), World Energy Outlook.

Kim, D. and Perron, P. (2009), "Unit root test allowing for a break in the trend function under both the null and alternative hypothesis", Journal of Econometrics, 148: 1-13.

Ketenci, N. (2016), "The bilateral trade flows of the EU in the presence of structural breaks", Empirical Economics, 51: 1369-1398.

Kleit A. (1998), "Did open access integrate natural gas markets? An arbitrage cost approach", Journal of Regulatory Economics, 14: 19-33.

Kwiatkowski, D., Phillips, P.C.B., Schmidt, P., Shin, Y., (1992). "Testing the null hypothesis of stationarity against the alternative of a unit root: how sure are we that economic time series have a unit root?", Journal of Econometrics, 541: 159-178.

Lee, J. and Strazicich, M.C. (2003), "Minimum LM unit root test with two structural breaks", Review of Economics and Statistics, 63: 1082-1089.

Li R., Joyeux R. and R.D Ripple (2014), “International natural gas market integration", The Energy Journal, 35(4): 159-179.

Lo, M.C. and Zivot, E. (2001), "Threshold cointegration and nonlinear adjustment to the law of one price", Macroeconomics Dynamics, 5(4): 533-576.

Maki, D. (2012), "Tests for cointegration allowing for an unknown number of breaks", Economic Modelling, 29(5): 2011-2015.

Neumann, A. (2009), "Linking natural gas markets - is LNG doing its job?", The Energy Journal, 30 (Special Issue): 187-199.

Nick, S. and Tischler, B. (2014). "The Law of one Price in Global Natural Gas Markets - A Threshold Cointegration Analysis”, EWI Working Papers, ${ }^{\circ}{ }^{14 / 16}$, Energiewirtschaftliches Institut.

Oglend, A., Lindback, M. and Osmundsen, P. (2015), "Shale Gas Boom Affecting the Relationship Between LPG and Oil Prices”, The Energy Journal, 36(4): 265-286.

Perron, P. (1989), "The great crash, the oil price shock, and the unit root hypothesis", Econometrica, 57(6): 1361-1401.

Perron, P. and Yabu, T. (2009), "Testing for shifts in trend with an integrated or stationary noise component", Journal of Business and Economics Statistics, 27: 369-396.

Petrovich B. (2015), "The cost of price de-linkages between European gas hubs", OIES Working Paper, NG 101, Oxford Institute for Energy Studies Papers. 
Phillips, P.C., Wu, Y. and Yu, J. (2011), "Explosive behaviour in the 1990s NASDAQ: When did exuberance escalate asset values?", International Economic Review, 52(1): 201-226.

Phillips, P.C., Shi, S. and Yu, J. (2015), "Testing for multiple bubbles: Historical episodes of exuberance and collapse in the S\&P 500”, International Economic Review, 56(4): 1043-1078.

Renou-Maissant P. (2012), "Toward the integration of European natural gas markets: A timevarying approach", Energy Policy, 51: 779-790.

Ramberg D. and Parsons, J. (2012) “The Weak Tie Between Natural Gas and Oil Prices”, The Energy Journal, 33(2): 13-35.

Ritz R. (2014), "Price Discrimination and Limits to Arbitrage: An Analysis of Global LNG Markets", Energy Economics, 45: 324-32.

Rogers H. (2015), « The impact of lower gas and oil prices on global gas and LNG markets », OIES Papers, NG 99, Oxford Institute for Energy Studies Papers.

Siliverstos, B., L’Hégaret, G., Neumann, A. and von Hirschhausen C. (2005), “International market integration for natural gas? A cointegration analysis of prices in Europe, North America and Japan", Energy Economics, 27: 603-615.

Spulber, D., and Doane, M. (1994), "Open access and the evolution of the US Spot market for natural gas", Journal of Law and Economics, 37(2): 477-518.

Sun, C. (2011), "Price dynamics in the import wooden bed market of the United States", Forest Policy 13(6): 479-487.

Wane, A., Gilbert, S. and Dibooglu, S. (2004), "Critical values of the empirical F-distribution for threshold autoregressive and momentum threshold models", Discussion Papers, 2004-13, Department of Economics, Southern Illinois University.

Zivot, E. and Andrews, D. (1992), "Further evidence of great crash, the oil price shock and unit root hypothesis", International Economic Review, 39: 1073-1100. 


\section{Appendix}

Figure 1. Prices for the European market (In euro per megawatt-hour, MWh)

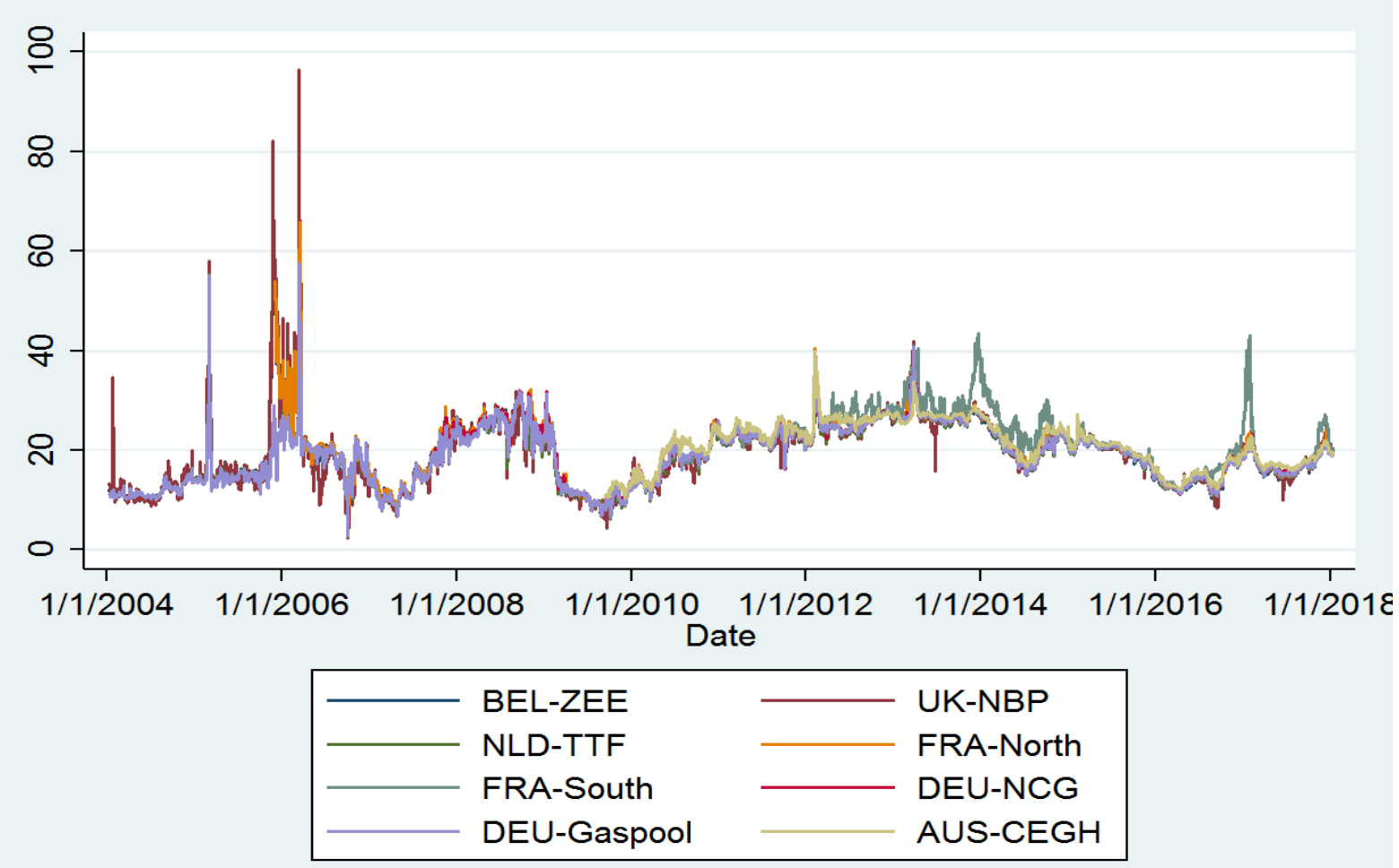

Figure 2. Prices for UK National Balancing Point, US Henry Hub and Japan-Korean Marker (In euro per megawatt-hour, MWh)

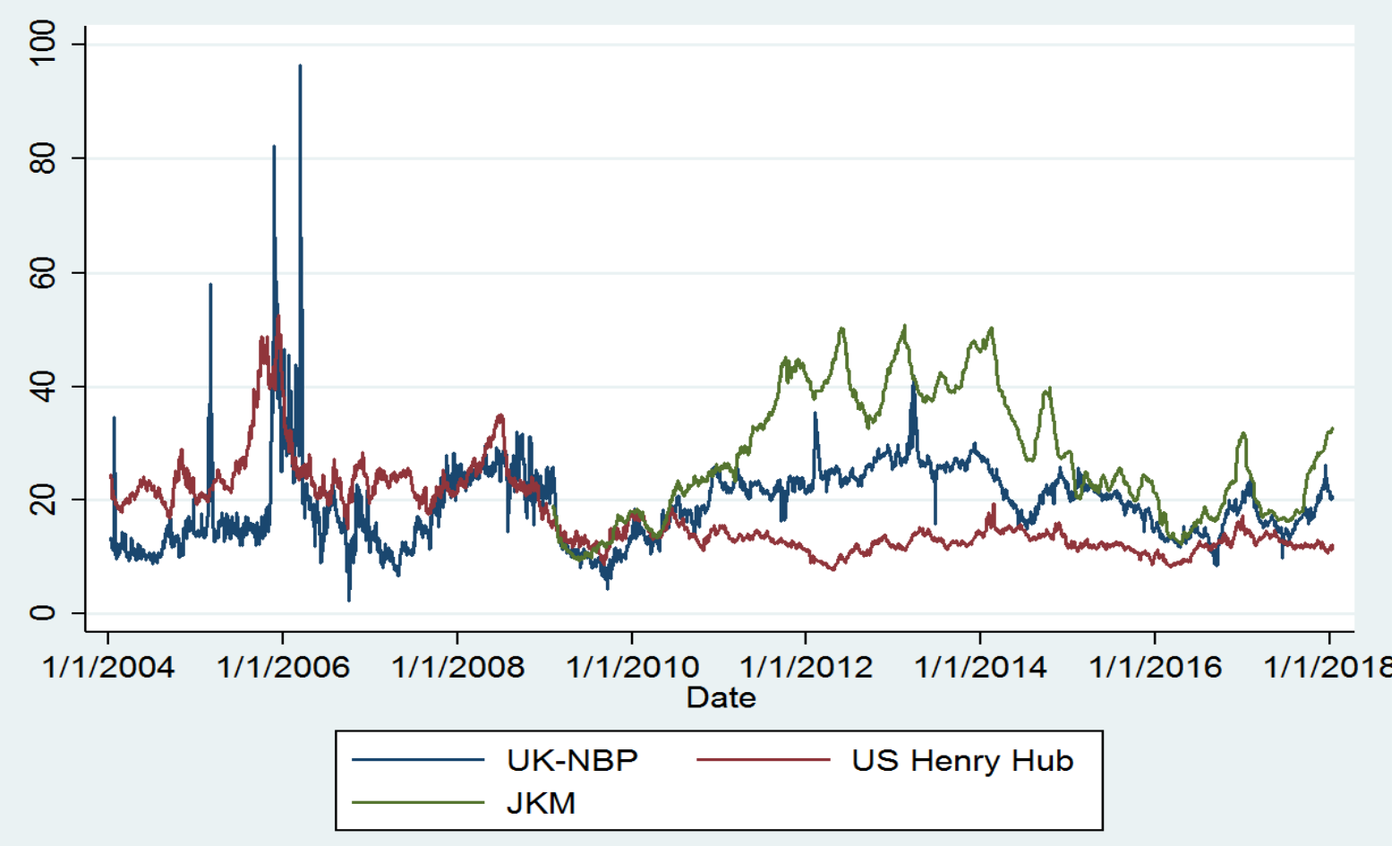


Figure 3. Prices for NBP (Euro per MWh), Henry Hub (Euro per MWh), Coal (Euro per ton and Oil (Index)

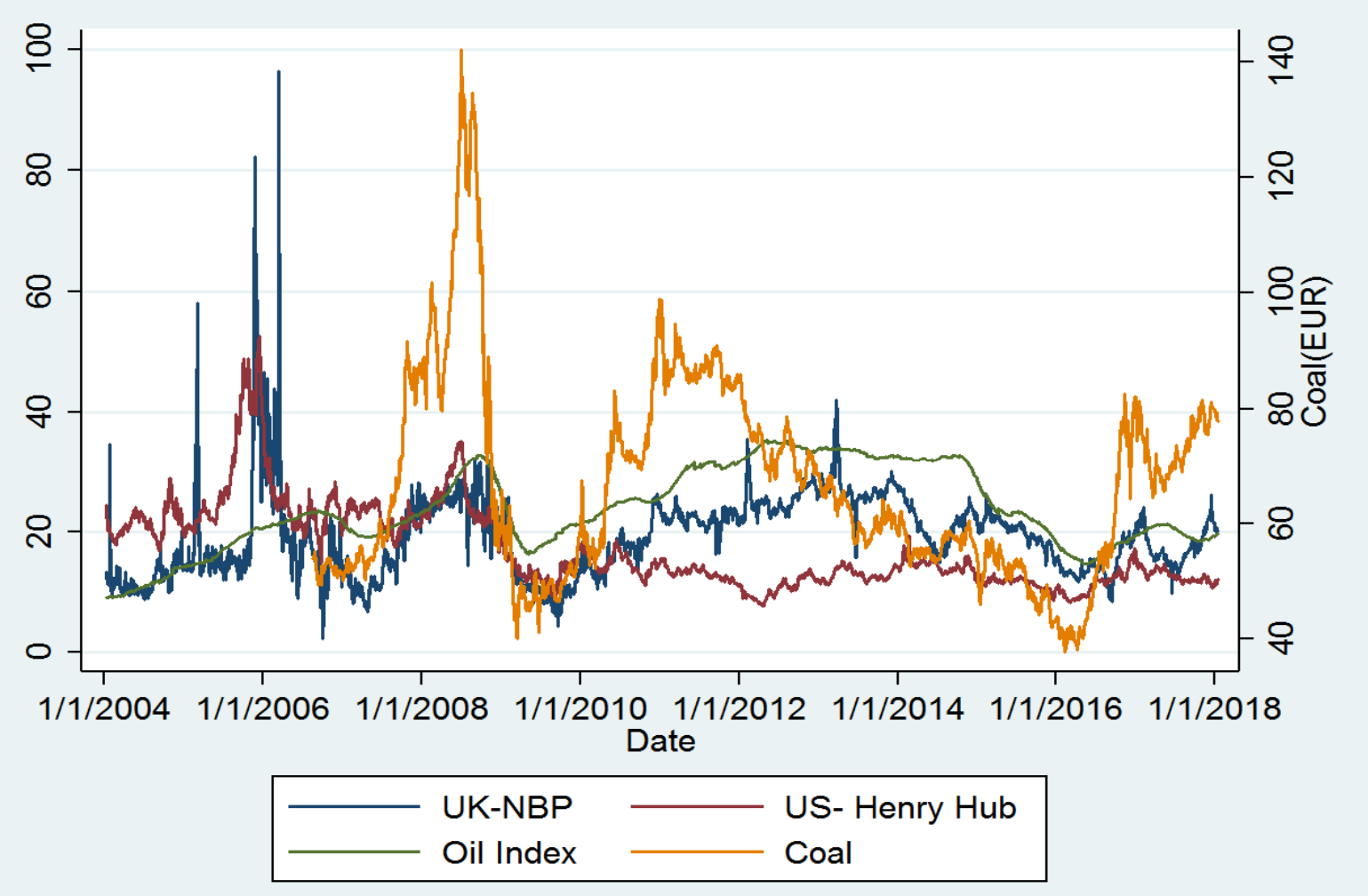




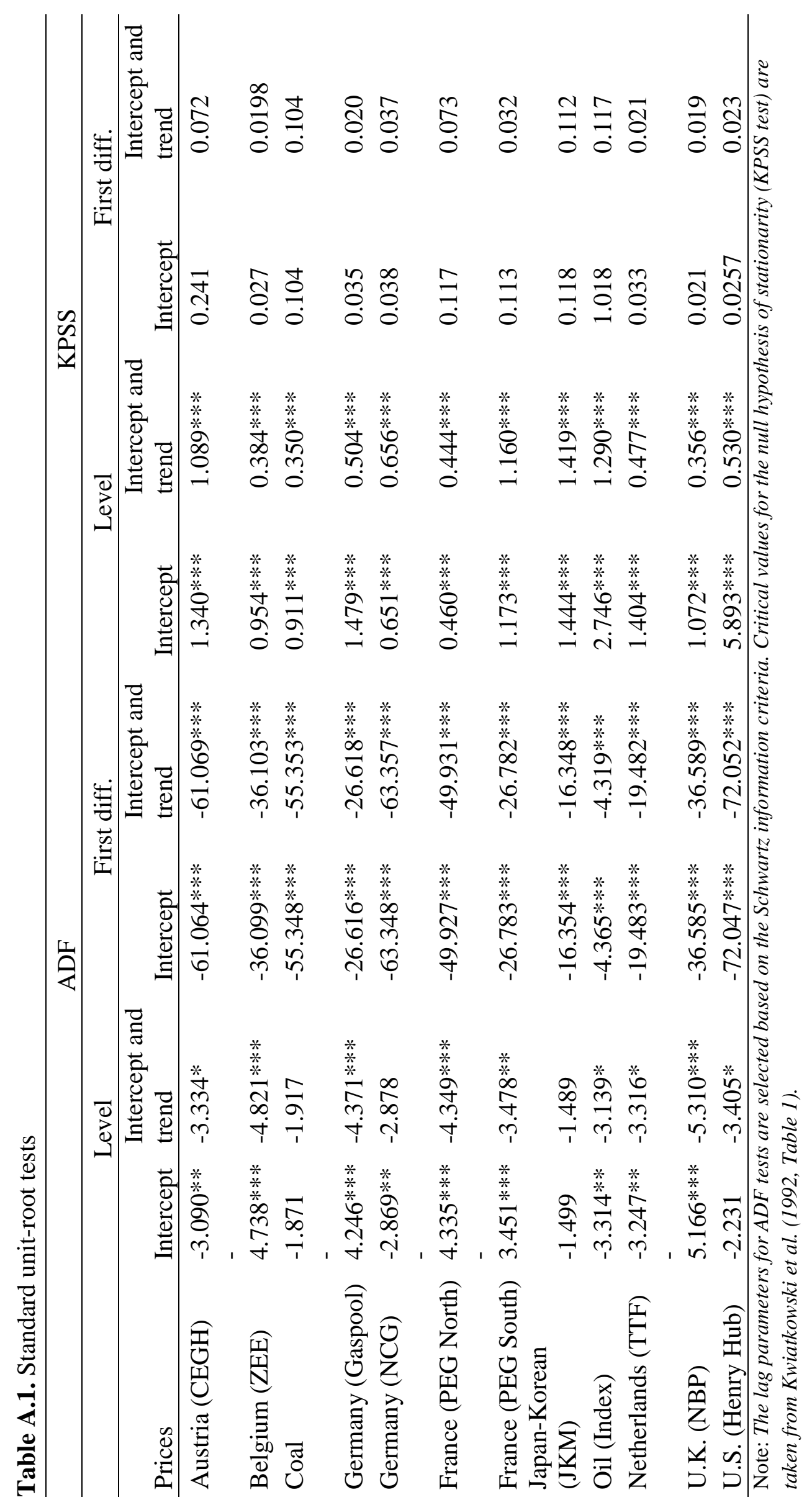


Table A.2. Results of the Gregory and Hansen (1996b) on cointegration with one structural break for the European gas market

\begin{tabular}{|c|c|c|c|c|c|}
\hline & $\mathrm{ADF}$ & $\mathrm{Z}_{\mathrm{t}}$ & $\mathrm{Z}_{\mathrm{a}}$ & Break date & Observations \\
\hline ZEE-NBP & $-17.33 * * *$ & $-20.33 * * *$ & $-837.07 * * *$ & $23 / 06 / 2006$ & $12 / 01 / 2004-12 / 01 / 2018$ \\
\hline TTF-NBP & $-13.70 * * *$ & $-24.40 * * *$ & $-1159.48 * * *$ & 04/10/2006 & $12 / 01 / 2004-12 / 01 / 2018$ \\
\hline PEG North-NBP & $-11.96 * * *$ & $-22.07 * * *$ & $-878.53 * * *$ & 28/04/2008 & $01 / 12 / 2005-12 / 01 / 2018$ \\
\hline PEG South-NBP & $-10.15^{* * *}$ & $-10.83 * * *$ & $-278.23 * * *$ & $24 / 10 / 2014$ & 25/09/2009-12/01/2018 \\
\hline NCG-NBP & $-14.87 * * *$ & $-17.79 * * *$ & $-750.36 * * *$ & $05 / 11 / 2009$ & 01/10/2007-12/01/2018 \\
\hline Gaspool-NBP & $-13.64 * * *$ & $-23.72 * * *$ & $-1112.41 * * *$ & 04/10/2006 & $12 / 01 / 2004-12 / 01 / 2018$ \\
\hline CEGH- NBP & $-8.09 * * *$ & $-9.74 * * *$ & $-216.39 * * *$ & $28 / 05 / 2016$ & $14 / 09 / 2009-12 / 01 / 2018$ \\
\hline ZEE-TTF & $-11.03 * * *$ & $-21.56 * * *$ & $-981.06 * * *$ & $15 / 12 / 2006$ & $12 / 01 / 2004-12 / 01 / 2018$ \\
\hline PEG North-TTF & $-13.55 * * *$ & $-21.87 * * *$ & $-968.25 * * *$ & 07/09/2006 & $01 / 12 / 2005-12 / 01 / 2018$ \\
\hline PEG South-TTF & $-7.51 * * *$ & $-10.91 * * *$ & $-296.26 * * *$ & $21 / 10 / 2014$ & $25 / 09 / 2009-12 / 01 / 2018$ \\
\hline NCG-TTF & $-13.37 * * *$ & $-30.22 * * *$ & $-1468.06 * * *$ & $31 / 03 / 2009$ & $12 / 01 / 2018$ \\
\hline Gaspool-TTF & $-15.13 * * *$ & $-33.84 * * *$ & $-1894.50 * * *$ & $22 / 04 / 2008$ & $12 / 01 / 2004-12 / 01 / 2018$ \\
\hline CEGH-TTF & $-10.15^{* * *}$ & $-11.95^{* * *}$ & $-312.98 * * *$ & $06 / 02 / 2015$ & $14 / 09 / 2009-12 / 01 / 2018$ \\
\hline ZEE-Gaspool & $-11.11 * * *$ & $-20.96 * * *$ & $-935.59 * * *$ & $15 / 12 / 2006$ & $12 / 01 / 2004-12 / 01 / 2018$ \\
\hline PEG North- Gasp & $-13.34 * * *$ & $-21.85 * * *$ & $-966.24 * * *$ & $06 / 10 / 2008$ & $12 / 01 / 2018$ \\
\hline PEG South- Gaspool & $-7.48 * * *$ & $-10.66 * * *$ & $-286.53 * * *$ & $21 / 10 / 2014$ & 25/09/2009-12/01/2018 \\
\hline NCG-Gaspool & $-15.20 * * *$ & $-33.70 * * *$ & $-1764.24 * * *$ & $31 / 03 / 2009$ & 01/10/2007-12/01/2018 \\
\hline CEGH-Gaspool & $-9.65 * * *$ & $-13.17 * * *$ & $-367.23 * * *$ & $06 / 02 / 2015$ & $14 / 09 / 2009-12 / 01 / 2018$ \\
\hline ZEE-NCG & $-19.28 * * *$ & $-27.61 * * *$ & $-1238.96 * * *$ & $07 / 11 / 2009$ & 01/10/2007-12/01/2018 \\
\hline PEG North-NCG & $-15.11 * * *$ & $-28.06 * * *$ & $-1316.64 * * *$ & $20 / 09 / 2010$ & 01/10/2007-12/01/2018 \\
\hline PEG South-NCG & $-7.40 * * *$ & $-10.87 * * *$ & $-295.60 * * *$ & $21 / 10 / 2014$ & 25/09/2009-12/01/2018 \\
\hline CEGH-NCG & $-9.64 * * *$ & $-11.93 * * *$ & $-331.54 * * *$ & $24 / 05 / 2016$ & $14 / 09 / 2009-12 / 01 / 2018$ \\
\hline ZEE-PEG North & $-14.36 * * *$ & $-28.86 * * *$ & $-1376.92 * * *$ & $27 / 09 / 2007$ & $01 / 12 / 2005-12 / 01 / 2018$ \\
\hline PEG South-PEG North & $-7.75 * * *$ & $-12.34 * * *$ & $-367.58 * * *$ & $21 / 10 / 2014$ & 25/09/2009-12/01/2018 \\
\hline CEGH-PEG North & $-8.35 * * *$ & $-11.24 * * *$ & $-306.84 * * *$ & $28 / 05 / 2016$ & $14 / 09 / 2009-12 / 01 / 2018$ \\
\hline ZEE-PEG South & $-7.44 * * *$ & $-11.07 * * *$ & $-303.99 * * *$ & $21 / 10 / 2014$ & 25/09/2009-12/01/2018 \\
\hline CEGH-PEG South & $-6.79 * * *$ & $-9.12 * * *$ & $-211.93 * * *$ & $08 / 10 / 2014$ & 25/09/2009-12/01/2018 \\
\hline ZEE-CEGH & $-8.21 * * *$ & $-11.83 * * *$ & $-294.13 * * *$ & 08/02/2011 & $14 / 09 / 2009-12 / 01 / 2018$ \\
\hline
\end{tabular}

Note: We consider the test that allows a break in the constant, the slope and the trend. The asterisks $* * *, * *$ and $*$ denote the rejection of the null hypothesis at the 1\%, 5\% and 10\% levels, respectively. The critical values are taken from Table 1 of Gregory and Hansen (1996b). 
Table A.3. Test for explosive behaviour of Phillips, Shi and Yu (2015) based on weekly data

\begin{tabular}{|c|c|c|c|c|c|}
\hline Prices & $\begin{array}{c}\text { Test } \\
\text { statistic }\end{array}$ & $\begin{array}{c}\text { Critical } \\
\text { value }(1 \%)\end{array}$ & $\begin{array}{c}\text { Critical } \\
\text { value }(5 \%)\end{array}$ & $\begin{array}{c}\text { Critical } \\
\text { value }(10 \%)\end{array}$ & Model \\
\hline Austria (CEGH) & 2.089 & 4.108 & 3.514 & 3.233 & None \\
\hline Belgium (ZEE) & 1.218 & 1.962 & 1.495 & 1.314 & $\begin{array}{l}\text { Intercept } \\
\text { and trend }\end{array}$ \\
\hline Coal & 2.761 & 4.258 & 3.617 & 3.314 & None \\
\hline Germany (Gaspool) & 1.313 & 1.962 & 1.495 & 1.314 & $\begin{array}{l}\text { Intercept } \\
\text { and trend }\end{array}$ \\
\hline Germany (NCG) & 1.936 & 4.058 & 3.619 & 3.351 & None \\
\hline France (PEG North) & 1.032 & 1.988 & 1.460 & 1.193 & $\begin{array}{l}\text { Intercept } \\
\text { and trend }\end{array}$ \\
\hline France (PEG South) & 2.870 & 3.991 & 3.494 & 3.258 & None \\
\hline $\begin{array}{c}\text { Japan-Korean } \\
(\mathrm{JKM})\end{array}$ & 0.816 & 1.912 & 1.440 & 1.193 & $\begin{array}{l}\text { Intercept } \\
\text { and trend }\end{array}$ \\
\hline Oil (Index) & 9.297 & 4.033 & 3.546 & 3.189 & None \\
\hline Netherlands (TTF) & 0.804 & 1.962 & 1.495 & 1.314 & $\begin{array}{l}\text { Intercept } \\
\text { and trend }\end{array}$ \\
\hline U.K. (NBP) & 0.749 & 1.962 & 1.495 & 1.314 & $\begin{array}{l}\text { Intercept } \\
\text { and trend }\end{array}$ \\
\hline U.S. (Henry Hub) & 0.254 & 1.962 & 1.495 & 1.314 & $\begin{array}{l}\text { Intercept } \\
\text { and trend }\end{array}$ \\
\hline
\end{tabular}

Note: The lag parameters for the test are selected based on the Schwartz information criteria. Critical values for the null hypothesis are obtained after 500 Monte Carlo simulations. The choice of the model retained is based on the significance of the trend and/or the intercept at the $5 \%$ level.

Table A.4. Perron-Yabu test for structural changes in the deterministic components based on weekly data

\begin{tabular}{lccccc}
\hline & Exp- W-RQF & Break date & $\mathrm{cv}(1 \%)$ & $\mathrm{cv}(5 \%)$ & $\mathrm{cv}(10 \%)$ \\
\hline Panel A: Gas prices & & & & & \\
Belgium (ZEE) & 15.011 & $2^{\text {nd }} 11 / 2010$ & 4.47 & 3.12 & 2.48 \\
U.K. $($ NBP) & 23.302 & $3^{\text {rd }} 11 / 2010$ & 4.47 & 3.12 & 2.48 \\
France (PEG South) & 19.003 & $3^{\text {rd }} 02 / 2014$ & 4.48 & 3.13 & 2.49 \\
France (PEG North) & 8.123 & $1^{\text {st }} 12 / 2010$ & 4.48 & 3.13 & 2.49 \\
Austria (CEGH) & 31.614 & $4^{\text {th }} 10 / 2011$ & 4.48 & 3.13 & 2.49 \\
Netherlands $($ TTF) & 13.964 & $3^{\text {rd }} 11 / 2010$ & 4.48 & 3.13 & 2.49 \\
Germany (Gaspool) & 15.185 & $3^{\text {rd }} 11 / 2010$ & 4.48 & 3.13 & 2.49 \\
Germany (NCG) & 14.376 & $1^{\text {st }} 05 / 2010$ & 4.48 & 3.13 & 2.49 \\
U.S. (Henry Hub) & 4.977 & $1^{\text {st }} 12 / 2008$ & 4.48 & 3.13 & 2.49 \\
Japan-Korean (JKM) & 7.958 & $1^{\text {st }} 06 / 2012$ & 4.48 & 3.13 & 2.49 \\
Panel B: Oil and Coal & & & & & \\
Oil & 13.932 & $3^{\text {rd }} 12 / 2014$ & 4.48 & 3.13 & 2.49 \\
Coal & 4.263 & $2^{\text {nd }} 10 / 2008$ & 4.48 & 3.13 & 2.49 \\
\hline Note:
\end{tabular}

Note: Trimmer parameter is equal to 0.15. The critical values are taken Table 2c of Perron and Yabu (2009). 
Table A.5. Results of Carrion-i-Silvestre et al. (2009) unit root tests with structural breaks based on weekly data

\begin{tabular}{|c|c|c|c|c|c|c|}
\hline & $\mathrm{P}_{\mathrm{T}}^{\mathrm{GLS}}$ & $\mathrm{MP}_{\mathrm{T}}^{\mathrm{GLS}}$ & $\mathrm{MZ}_{\alpha}^{\mathrm{GLS}}$ & $\mathrm{MSB}^{\mathrm{GLS}}$ & $\mathrm{MZ}_{\mathrm{t}}^{\mathrm{GLS}}$ & Numbers of breaks \\
\hline \multirow[t]{2}{*}{ Austria (CEGH) } & 11.98 & 11.59 & -31.76 & 0.125 & -3.98 & 4 \\
\hline & {$[6.99]$} & [6.99] & {$[-49.59]$} & {$[0.100]$} & {$[-4.96]$} & \\
\hline \multirow[t]{2}{*}{ Belgium (ZEE) } & 15.84 & 13.44 & -25.54 & 0.139 & -3.73 & 4 \\
\hline & {$[6.83]$} & {$[6.83]$} & {$[-47.84]$} & {$[0.101]$} & {$[-4.84]$} & \\
\hline \multirow[t]{2}{*}{ Netherlands (TTF) } & 13.78 & 13.46 & -25.75 & 0.139 & -3.57 & 4 \\
\hline & {$[6.41]$} & {$[6.41]$} & {$[-50.66]$} & {$[0.099]$} & {$[-5.01]$} & \\
\hline \multirow[t]{2}{*}{ U.K. (NBP) } & 9.105 & 8.57 & -42.13 & 0.109 & -4.59 & 4 \\
\hline & {$[6.67]$} & {$[6.67]$} & {$[-50.28]$} & {$[0.099]$} & {$[-5.01]$} & \\
\hline \multirow[t]{2}{*}{ France (PEG North) } & 20.61 & 19.11 & -18.43 & 0.165 & -3.03 & 4 \\
\hline & {$[6.52]$} & {$[6.52]$} & {$[-50.27]$} & [0.099] & {$[-5.00]$} & \\
\hline \multirow[t]{2}{*}{ France (PEG South) } & 14.87 & 11.92 & -29.63 & 0.130 & -3.85 & 4 \\
\hline & [6.69] & [6.69] & [-49.63] & {$[0.100]$} & {$[-4.97]$} & \\
\hline \multirow[t]{2}{*}{ Japan-Korean (JKM) } & 13.36 & 12.70 & -18.44 & 0.164 & -3.02 & 3 \\
\hline & {$[5.04]$} & {$[5.04]$} & {$[-44.13]$} & [0.107] & {$[-4.68]$} & \\
\hline \multirow[t]{2}{*}{ U.S. (Henry Hub) } & 67.51 & 59.22 & -6.52 & 0.276 & -1.80 & 4 \\
\hline & {$[6.96]$} & {$[6.96]$} & {$[-51.12]$} & {$[0.099]$} & {$[-5.04]$} & \\
\hline \multirow[t]{2}{*}{ Germany (Gaspool) } & 14.18 & 13.86 & -24.97 & 0.141 & -3.52 & 4 \\
\hline & {$[6.41]$} & {$[6.41]$} & {$[-50.66]$} & [0.099] & {$[-5.01]$} & \\
\hline \multirow[t]{2}{*}{ Germany (NCG) } & 23.35 & 21.69 & -16.58 & 0.174 & -2.88 & 4 \\
\hline & {$[6.67]$} & {$[6.67]$} & {$[-50.57]$} & [0.099] & {$[-5.02]$} & \\
\hline \multirow[t]{2}{*}{ Oil (Index) } & 55.67 & 50.96 & -8.48 & 0.241 & -2.04 & 5 \\
\hline & [6.92] & {$[6.92]$} & {$[-56.94]$} & [0.093] & {$[-5.33]$} & \\
\hline \multirow[t]{2}{*}{ Coal } & 40.65 & 38.58 & -9.26 & 0.231 & -2.14 & 4 \\
\hline & [7.07] & [7.07] & {$[-47.25]$} & {$[0.112]$} & {$[-4.83]$} & \\
\hline
\end{tabular}

Note: Critical values for the $1 \%$ level significance are in brackets. The test is implemented for model III, where the structural break affects both the level and the slope of the time trend. $P_{T}^{G L S}$ is the feasible point optimal test, $M P_{T}^{G L S}$ is the modified point optimal test, $M Z_{\alpha}^{G L S}$ is the modified Phillips-Perron $M Z_{\alpha}$ test, $M S B^{G L S}$ is the modified Sargan-Bhargava test and $M Z_{t}^{G L S}$, is the modified Phillips-Perron $M Z_{t}$ test. 


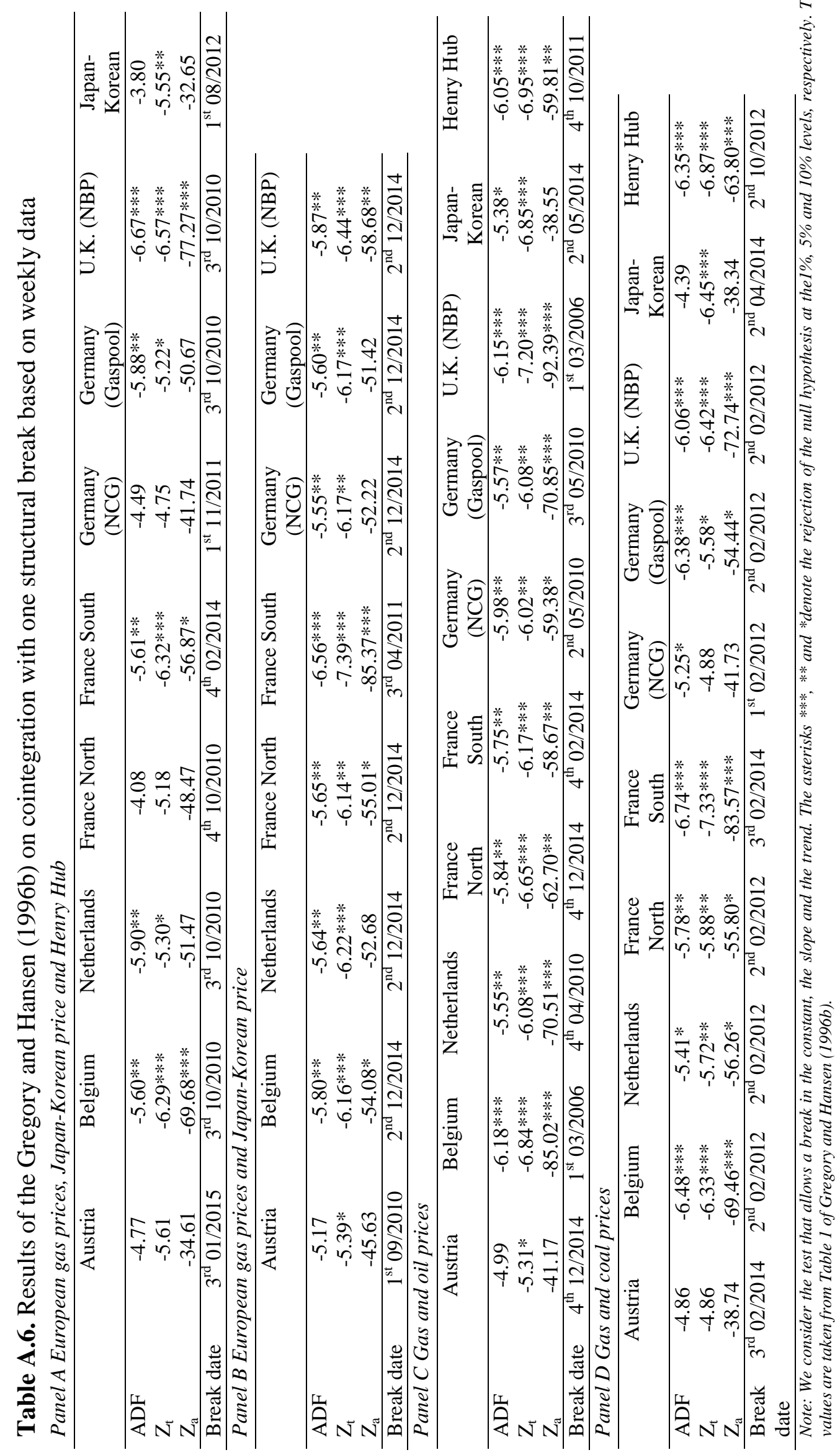


Table A.7. Results of the Gregory and Hansen (1996b) on cointegration with one structural break for the European gas market based on weekly data

\begin{tabular}{|c|c|c|c|c|}
\hline & $\mathrm{ADF}$ & $\mathrm{Z}_{\mathrm{t}}$ & $\mathrm{Z}_{\mathrm{a}}$ & Break date \\
\hline ZEE-NBP & $-10.02 * * *$ & $-14.53 * * *$ & $-319.56 * * *$ & $1^{\text {st }} 06 / 2006$ \\
\hline TTF-NBP & $-11.11 * * *$ & $-12.33 * * *$ & $-252.13 * * *$ & $4^{\text {th }} 09 / 2006$ \\
\hline PEG North-NBP & $-10.47 * * *$ & $-10.66 * * *$ & $-190.54 * * *$ & $3^{\text {rd }} 09 / 2007$ \\
\hline PEG South-NBP & $-8.14 * * *$ & $-7.45 * * *$ & $-95.07 * * *$ & $1^{\text {st }} 11 / 2014$ \\
\hline NCG-NBP & $-9.87 * * *$ & $-9.90 * * *$ & $-165.86 * * *$ & $1^{\text {st }} 11 / 2009$ \\
\hline Gaspool-NBP & $-10.81 * * *$ & $-11.93 * * *$ & $-238.81 * * *$ & $3^{\text {rd }} 09 / 2006$ \\
\hline CEGH- NBP & $-6.07 * * *$ & $-6.21 * * *$ & $-66.96 * *$ & $4^{\text {th }} 08 / 2016$ \\
\hline ZEE-TTF & $-11.65 * * *$ & $-10.33 * * *$ & $-189.04 * * *$ & $2^{\text {nd }} 03 / 2006$ \\
\hline PEG North-TTF & $-9.73 * * *$ & $-11.41 * * *$ & $-179.31 * * *$ & $3^{\text {rd }} 07 / 2008$ \\
\hline PEG South-TTF & $-6.78 * * *$ & $-6.91 * * *$ & $-83.10 * * *$ & $1^{\text {st }} 11 / 2014$ \\
\hline NCG-TTF & $-11.70 * * *$ & $-12.05 * * *$ & $-224.50 * * *$ & $1^{\text {st }} 04 / 2009$ \\
\hline Gaspool-TTF & $-13.06 * * *$ & $-13.55 * * *$ & $-287.46 * * *$ & $1^{\text {st }} 04 / 2008$ \\
\hline CEGH-TTF & $-5.85 * *$ & $-8.03 * * *$ & $-107.13 * * *$ & $1^{\text {st }} 02 / 2015$ \\
\hline ZEE-Gaspool & $-10.90 * * *$ & $-10.52 * * *$ & $-193.63 * * *$ & $2^{\text {nd }} 03 / 2006$ \\
\hline PEG North- Gaspool & $-12.75 * * *$ & $-11.25 * * *$ & $-175.30 * * *$ & $1^{\text {st }} 11 / 2008$ \\
\hline PEG South- Gaspool & $-7.70 * * *$ & $-7.08 * * *$ & $-82.10 * * *$ & $1^{\text {st }} 10 / 2014$ \\
\hline NCG-Gaspool & $-12.82 * * *$ & $-13.38 * * *$ & $-261.18 * * *$ & $1^{\text {st }} 04 / 2009$ \\
\hline CEGH-Gaspool & $-5.24 *$ & $-8.40 * * *$ & $-117.19 * * *$ & $4^{\text {th }} 01 / 2015$ \\
\hline ZEE-NCG & $-13.05 * * *$ & $-13.40 * * *$ & $-265.67 * * *$ & $2^{\text {nd }} 11 / 2009$ \\
\hline PEG North-NCG & $-11.66 * * *$ & $-11.88 * * *$ & $-221.54 * * *$ & $4^{\text {th }} 09 / 2010$ \\
\hline PEG South-NCG & $-7.77 * * *$ & $-6.66 * * *$ & $-80.77 * * *$ & $3^{\text {rd }} 10 / 2014$ \\
\hline CEGH-NCG & $-5.52 * *$ & $-7.95 * * *$ & $-105.56 * * *$ & $2^{\text {nd }} 05 / 2016$ \\
\hline ZEE-PEG North & $-12.26 * * *$ & $-12.15 * * *$ & $-243.28 * * *$ & $2^{\text {nd }} 09 / 2007$ \\
\hline PEG South-PEG North & $-8.05 * * *$ & $-6.80 * * *$ & $-85.79 * * *$ & $3^{\text {rd }} 09 / 2014$ \\
\hline CEGH-PEG North & $-5.48 *$ & $-7.66 * * *$ & $-100.70 * * *$ & $2^{\text {nd }} 09 / 2016$ \\
\hline ZEE-PEG South & $-6.97 * * *$ & $-6.77 * * *$ & $-84.69 * * *$ & $4^{\text {th }} 10 / 2014$ \\
\hline CEGH-PEG South & $-6.79 * * *$ & $-9.12 * * *$ & $-211.93 * * *$ & $4^{\text {th }} 09 / 2014$ \\
\hline ZEE-CEGH & $-6.21 * * *$ & $-7.57 * * *$ & $-100.38 * * *$ & $1^{\mathrm{st}} 02 / 2011$ \\
\hline
\end{tabular}

Note: We consider the test that allows a break in the constant, the slope and the trend. The asterisks ***, ** and *denote the rejection of the null hypothesis at the 1\%, 5\% and 10\% levels, respectively. The critical values are taken from Table 1 of Gregory and Hansen (1996b). 
Table A.8. Maki's (2012) bivariate cointegration tests results based on weekly data

\begin{tabular}{|c|c|c|c|}
\hline \multicolumn{4}{|c|}{ European gas prices and JKM with U.S. Henry Hub } \\
\hline & Statistics & Critical value & Break dates \\
\hline Belgium (ZEE) & $-6.874 * *$ & -6.524 & $4^{\text {th }} 09 / 2006 ; 3^{\text {rd }} 02 / 2009 ; 2^{\text {nd }} 01 / 2014$ \\
\hline U.K. $(N B P)$ & $-6.604 * *$ & -6.524 & $4^{\text {th }} 05 / 2006 ; 1^{\text {st }} 11 / 2008 ; 4^{\text {th }} 03 / 2013$ \\
\hline Netherlands (TTF) & $-6.759 * *$ & -6.524 & $2^{\text {nd }} 09 / 2006 ; 2^{\text {nd }} 02 / 2009 ; 2^{\text {nd }} 01 / 2014$ \\
\hline Germany (Gaspool) & $-6.357 *$ & -6.524 & $2^{\text {nd }} 09 / 2006 ; 1^{\text {st }} 02 / 2009 ; 4^{\text {th }} 10 / 2014$ \\
\hline Germany $(N C G)$ & -6.141 & -6.524 & $3^{\text {rd }} 02 / 2009 ; 2^{\text {nd }} 08 / 2015 ; 1^{\text {st }} 12 / 2016$ \\
\hline Japan-Korean & -4.561 & -6.524 & \\
\hline Austria $(C E G H)$ & -5.519 & -6.524 & \\
\hline France (PEG South) & $-6.432 *$ & -6.524 & $2^{\text {nd }} 10 / 2011 ; 3^{\text {rd }} 04 / 2013 ; 1^{\text {st }} 01 / 2016$ \\
\hline France (PEG North) & -5.343 & -6.524 & \\
\hline \multicolumn{4}{|c|}{ Gas prices with oil } \\
\hline Belgium (ZEE) & $-6.805 * *$ & -6.524 & $3^{\text {rd }} 10 / 2006 ; 4^{\text {th }} 12 / 2009 ; 4^{\text {th }} 03 / 2013$ \\
\hline U.K. $(N B P)$ & $-7.060 * *$ & -6.524 & $3^{\text {rd }} 10 / 2006 ; 4^{\text {th }} 12 / 2009 ; 4^{\text {th }} 03 / 2013$ \\
\hline Netherlands (TTF) & $-7.112 * * *$ & -6.524 & $4^{\text {th }} 10 / 2006 ; 1^{\text {st }} 03 / 2011 ; 1^{\text {st }} 06 / 2015$ \\
\hline Germany (Gaspool) & $-7.178 * * *$ & -6.524 & $4^{\text {th }} 04 / 2007 ; 1^{\text {st }} 10 / 2009 ; 3^{\text {rd }} 03 / 2013$ \\
\hline Germany $(N C G)$ & -5.460 & -6.524 & $2^{\text {nd }} 10 / 2009 ; 2^{\text {nd }} 02 / 2012 ; 2^{\text {nd }} 04 / 2014$ \\
\hline Japan-Korean & -3.119 & -6.524 & \\
\hline Austria $(C E G H)$ & -4.782 & -6.524 & \\
\hline France (PEG South) & -6.228 & -6.524 & $4^{\text {th }} 10 / 2010 ; 1^{\text {st }} 02 / 2012 ; 2^{\text {nd }} 01 / 2017$ \\
\hline France (PEG North) & $-6.470 *$ & -6.524 & $1^{s t} 10 / 2009 ; 2^{\text {nd }} 02 / 2012 ; 3^{\text {rd }} 04 / 2014$ \\
\hline United States $(H H)$ & $-5.334 *$ & -5.541 & $3^{\text {rd }} 09 / 2012$ \\
\hline \multicolumn{4}{|c|}{ European gas prices with Japan Korean (JKM) } \\
\hline Belgium (ZEE) & $-5.609 * *$ & -5.541 & $4^{\text {th }} 11 / 2010$ \\
\hline$U . K .(N B P)$ & $-6.276^{*}$ & -6.524 & $3^{\text {rd }} 09 / 2010 ; 4^{\text {th }} 03 / 2013 ; 3^{\text {rd }} 12 / 2015$ \\
\hline Netherlands (TTF) & $-5.507 *$ & -5.541 & $4^{\text {th }} 11 / 2010$ \\
\hline Germany (Gaspool) & $-5.454 *$ & -5.541 & $4^{\text {th }} 11 / 2010$ \\
\hline Germany (NCG) & $-5.400 *$ & -5.541 & $4^{\text {th }} 11 / 2010$ \\
\hline Austria (CEGH) & -4.480 & -6.100 & \\
\hline France (PEG South) & $-6.853 * * *$ & -6.100 & $4^{\text {th }} 02 / 2011 ; 2^{\text {nd }} 04 / 2013$ \\
\hline France (PEG North) & $-5.649 * *$ & -5.541 & $4^{\text {th }} 11 / 2010$ \\
\hline
\end{tabular}

Note: Critical values at the 0.05 significance level are from Table 1 of Maki (2012). *, **, *** denotes the rejection of the null hypothesis of no cointegration. Break dates are obtained by using Maki's (2012) cointegration test. 
Table A.9. Estimation of long-term coefficients based on weekly data (DOLS, Bartlett Kernel, Newey-West fixed bandwidth)- European natural gas market

\begin{tabular}{|c|c|c|c|c|c|c|}
\hline \multirow[b]{3}{*}{ Austria (CEGH) } & \multicolumn{3}{|c|}{ With U.K. NBP } & \multicolumn{3}{|c|}{ With Netherlands TTF } \\
\hline & First period & $\begin{array}{l}\text { Second } \\
\text { period }\end{array}$ & Break date & First period & $\begin{array}{l}\text { Second } \\
\text { period }\end{array}$ & Break date \\
\hline & $\begin{array}{c}0.867 * * * \\
(0.039)\end{array}$ & $\begin{array}{c}0.575 * * * \\
(0.041)\end{array}$ & $4^{\text {th }} 08 / 2016$ & $\begin{array}{c}0.844 * * * \\
(0.030)\end{array}$ & $\begin{array}{c}0.900 * * * \\
(0.022)\end{array}$ & $1^{\text {st }} 02 / 2015$ \\
\hline$L O P$ & $11.42 * * *$ & $177.27 * * *$ & & $26.55 * * *$ & $21.42 * * *$ & \\
\hline Belgium (ZEE) & $\begin{array}{c}0.979 * * * \\
(0.007)\end{array}$ & $\begin{array}{c}0.980 * * * \\
(0.008)\end{array}$ & $1^{\text {st }} 06 / 2006$ & $\begin{array}{c}1.483 * * * \\
(0.120)\end{array}$ & $\begin{array}{c}1.026 * * * \\
(0.011)\end{array}$ & $2^{\text {nd }} 03 / 2006$ \\
\hline$L O P$ & $7.67 * * *$ & $5.68 * *$ & & $16.20 * * *$ & $5.82 * *$ & \\
\hline Netherlands (TTF) & $\begin{array}{c}0.675 * * * \\
(0.027)\end{array}$ & $\begin{array}{c}0.966 * * * \\
(0.015)\end{array}$ & $4^{\text {th }} 09 / 2006$ & & & \\
\hline$L O P$ & $139.08 * * *$ & $5.36 * *$ & & & & \\
\hline Germany (Gaspool) & $\begin{array}{c}0.709 * * * \\
(0.050)\end{array}$ & $\begin{array}{c}0.960 * * * \\
(0.015)\end{array}$ & $3^{\text {rd }} 09 / 2006$ & $\begin{array}{c}0.982 * * * \\
(0.004)\end{array}$ & $\begin{array}{c}0.991 * * * \\
(0.006)\end{array}$ & $1^{\text {st }} 04 / 2008$ \\
\hline$L O P$ & $33.85 * * *$ & $7.37 * * *$ & & $15.49 * * *$ & 2.35 & \\
\hline Germany (NCG) & $\begin{array}{c}0.968 * * * \\
(0.016)\end{array}$ & $\begin{array}{c}0.963 * * * \\
(0.022)\end{array}$ & $1^{\text {st }} 11 / 2009$ & $\begin{array}{c}0.960 * * * \\
(0.015)\end{array}$ & $\begin{array}{c}0.976 * * * \\
(0.007)\end{array}$ & $1^{\text {st }} 04 / 2009$ \\
\hline$L O P$ & $3.93 *$ & 2.60 & & $7.07 * * *$ & $10.12 * * *$ & \\
\hline France (PEG North) & $\begin{array}{c}0.852 * * * \\
(0.028)\end{array}$ & $\begin{array}{c}0.953 * * * \\
(0.017)\end{array}$ & $3^{\text {rd }} 09 / 2007$ & $\begin{array}{c}1.071 * * * \\
(0.045)\end{array}$ & $\begin{array}{c}0.996 * * * \\
(0.008)\end{array}$ & $3^{\text {rd }} 07 / 2008$ \\
\hline$L O P$ & $27.92 * * *$ & $7.91 * * *$ & & 2.54 & 0.263 & \\
\hline France (PEG South) & $\begin{array}{c}0.999 * * * \\
(0.029)\end{array}$ & $\begin{array}{c}0.901 * * * \\
(0.011)\end{array}$ & $1^{\text {st }} 11 / 2014$ & $\begin{array}{c}1.049 * * * \\
(0.030)\end{array}$ & $\begin{array}{c}0.956 * * * \\
(0.092)\end{array}$ & $1^{\text {st }} 11 / 2014$ \\
\hline$L O P$ & 0.000 & 0.740 & & 2.620 & 0.225 & \\
\hline
\end{tabular}




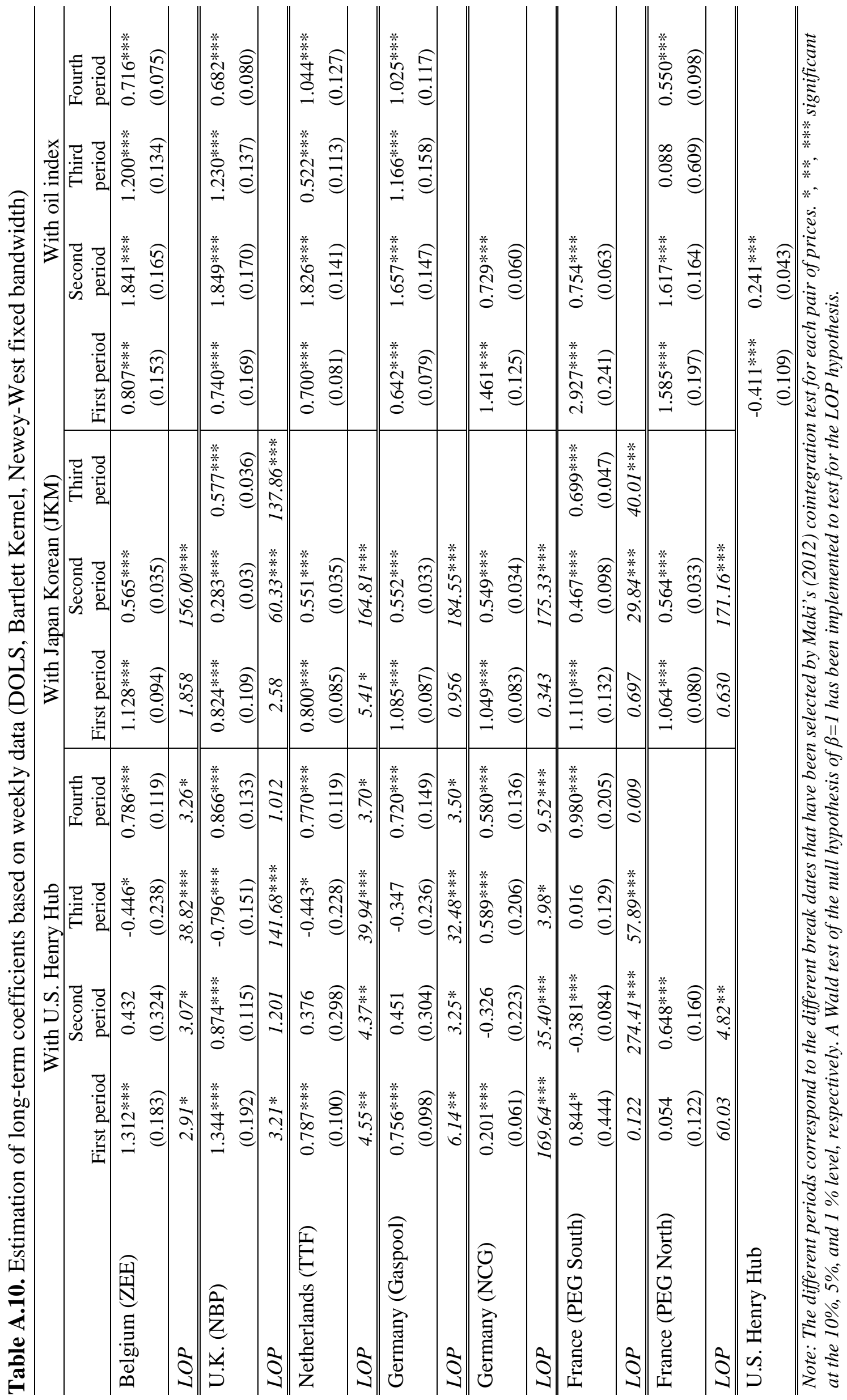


Table A.11. Threshold cointegration tests for natural gas based on weekly data (Enders and Siklos, 2001).

\begin{tabular}{ccccccc}
\hline & NBP and & Henry Hub & TTF and & NBP and & NBP and & TTF and \\
& Henry Hub & and JKM & Henry Hub & TTF & JKM & JKM \\
\hline Model & Consistent & Consistent & Consistent & Consistent & Consistent & Consistent \\
& MTAR & TAR & TAR & TAR & MTAR & MTAR \\
Lag & 2 & 2 & 2 & 0 & 2 & 2 \\
Threshold & -0.045 & -0.128 & 0.330 & -0.053 & 0.013 & -0.041 \\
$\rho_{1}$ & -0.017 & $-0.059^{* * *}$ & $-0.358^{* * *}$ & $-0.135 * * *$ & -0.024 & $-0.064 * *$ \\
& $(-1.343)$ & $(-4.375)$ & $(-4.738)$ & $(-5.442)$ & $(-0.978)$ & $(-3.607)$ \\
$\rho_{2}$ & $-0.104 * * *$ & $-0.025^{*}$ & $-0.078^{* * *}$ & $-0.259 * * *$ & $-0.133 * * *$ & $-0.146 * * *$ \\
& $(-4.976)$ & $(-1.882)$ & $(-5.056)$ & $(-6.862)$ & $(-6.634)$ & $(-1.693)$ \\
\hline AIC & -1250.00 & -2596.38 & -2144.87 & -2022.16 & -1987.00 & -2137.68 \\
BIC & -1227.06 & -2573.43 & -2121.92 & -2008.38 & -1963.53 & -2114.74 \\
$Q_{\mathrm{LB}}(4)$ & 0.867 & 0.199 & 0.483 & 0.063 & 0.967 & 0.505 \\
\hline$\Phi: \rho_{1}=\rho_{2}=0$ & 13.192 & 11.16 & 22.790 & 38.355 & 22.259 & 19.012 \\
Critical values & 6.47 & 6.44 & 6.44 & 6.47 & 6.47 & 6.47 \\
$(10 \%)$ & & & & & & 7.53 \\
Critical values & 7.53 & 7.47 & 7.47 & 7.53 & 7.53 & 7.53 \\
$(5 \%)$ & & & & & & \\
Critical values & 9.76 & 9.64 & 9.64 & 9.76 & 9.76 & 9.76 \\
$(1 \%)$ & & & & & & \\
F: $\rho_{1}=\rho_{2}$ & $12.563 * * *$ & $3.17 *$ & $13.460 * *$ & $7.623 * * *$ & $12.254 * * *$ & $6.219 * *$ \\
\hline
\end{tabular}

Note: $t$-statistics are in parentheses. $Q_{L B}$ is the Ljung-Box statistic for 4 lags. Critical values for the distribution of $\Phi$ come from Table 1 of Wane et al. (2004). Lags are chosen according to the BIC. *, **, *** denote significance at the 10\%, 5\%, and $1 \%$ levels, respectively. 
Table A.12. Results of the asymmetric error correction model with threshold cointegration based on weekly data (European and U.S. markets)

\begin{tabular}{|c|c|c|c|c|c|c|}
\hline & $\begin{array}{c}\text { U.K NBP } \\
\left(\Delta P_{t}^{1}\right)\end{array}$ & $\begin{array}{c}\text { U.S. HH } \\
\left(\Delta P_{t}^{2}\right)\end{array}$ & $\begin{array}{c}\text { Netherlands } \\
\text { TTF }\left(\Delta P_{t}^{3}\right)\end{array}$ & $\begin{array}{c}\text { U.S. HH } \\
\left(\Delta P_{t}^{2}\right)\end{array}$ & $\begin{array}{c}\text { U.K NBP } \\
\left(\Delta P_{t}^{1}\right)\end{array}$ & $\begin{array}{c}\text { Netherlands } \\
\text { TTF }\left(\Delta P_{t}^{3}\right)\end{array}$ \\
\hline \multirow[t]{2}{*}{$\Delta N B P_{t-1}^{+}$} & 0.082 & -0.006 & & & 0.007 & $0.128 *$ \\
\hline & $(0.062)$ & $(0.029)$ & & & $(0.096)$ & $(0.071)$ \\
\hline \multirow[t]{2}{*}{$\Delta N B P_{t-2}^{+}$} & $-0.244 * * *$ & 0.037 & & & -0.004 & -0.068 \\
\hline & $(0.062)$ & $(0.030)$ & & & $(0.095)$ & $(0.071)$ \\
\hline \multirow[t]{2}{*}{$\Delta N B P_{t-1}^{-}$} & 0.102 & 0.029 & & & $-0.168 *$ & $-0.206^{* * *}$ \\
\hline & $(0.066)$ & $(0.031)$ & & & $(0.101)$ & $(0.075)$ \\
\hline \multirow{2}{*}{$\Delta N B P_{t-2}^{-}$} & -0.054 & -0.023 & & & 0.030 & $0.153 * *$ \\
\hline & $(0.064)$ & $(0.010)$ & & & $(0.097)$ & $(0.072)$ \\
\hline \multirow[t]{2}{*}{$\Delta H H_{t-1}^{+}$} & 0.145 & $0.217 * * *$ & 0.086 & $-0.218 * * *$ & & \\
\hline & $(0.157)$ & $(0.074)$ & $(0.112)$ & $(0.075)$ & & \\
\hline \multirow[t]{2}{*}{$\Delta H H_{t-2}^{+}$} & -0.027 & -0.076 & -0.039 & -0.098 & & \\
\hline & $(0.157)$ & $(0.074)$ & $(0.112)$ & $(0.075)$ & & \\
\hline \multirow[t]{2}{*}{$\Delta H H_{t-1}^{-}$} & 0.132 & $0.466 * * *$ & 0.148 & $-0.480 * * *$ & & \\
\hline & $(0.165)$ & $(0.078)$ & $(0.112)$ & $(0.078)$ & & \\
\hline \multirow[t]{2}{*}{$\Delta H H_{t-2}^{-}$} & -0.062 & -0.091 & -0.110 & $-0.085^{* *}$ & & \\
\hline & $(0.166)$ & (0.079) & (0.118) & $(0.079)$ & & \\
\hline \multirow[t]{2}{*}{$\Delta T T F_{t-1}^{+}$} & & & $0.288 * * *$ & 0.047 & 0.142 & -0.028 \\
\hline & & & $(0.067)$ & $(0.045)$ & $(0.131)$ & $(0.097)$ \\
\hline \multirow[t]{2}{*}{$\Delta T T F_{t-2}^{+}$} & & & $-0.292 * *$ & 0.003 & $-0.485 * * *$ & $-0.283^{*} * *$ \\
\hline & & & $(0.064)$ & $(0.043)$ & $(0.133)$ & $(0.099)$ \\
\hline \multirow[t]{2}{*}{$\Delta T T F_{t-1}^{-}$} & & & $-0.233 * * *$ & -0.002 & $0.481 * * *$ & $0.495 * * *$ \\
\hline & & & $(0.066)$ & $(0.044)$ & $(0.138)$ & $(0.102)$ \\
\hline \multirow[t]{2}{*}{$\Delta T T F_{t-2}^{-}$} & & & $-0.164 * * *$ & -0.013 & -0.076 & $-0.331 * * *$ \\
\hline & & & $(0.064)$ & $(0.043)$ & $(0.136)$ & $(0.101)$ \\
\hline \multirow[t]{2}{*}{$E C M_{t-1}^{+}$} & -0.018 & -0.000 & $-0.493 * * *$ & -0.044 & -0.027 & $0.075 * *$ \\
\hline & $(0.013)$ & $(0.006)$ & $(0.079)$ & $(0.053)$ & $(0.048)$ & $(0.036)$ \\
\hline \multirow[t]{2}{*}{$E C M_{t-1}^{-}$} & $-0.103 * *$ & $0.027 * * *$ & $-0.022 * * *$ & -0.008 & $-0.326 * * *$ & -0.050 \\
\hline & $(0.021)$ & $(0.010)$ & (0.009) & $(0.006)$ & $(0.074)$ & $(0.055)$ \\
\hline \multirow[t]{2}{*}{ Intercept } & 0.003 & 0.000 & 0.002 & 0.004 & 0.007 & 0.005 \\
\hline & $(0.008)$ & $(0.001)$ & $(0.005)$ & $(0.004)$ & $(0.005)$ & $(0.004)$ \\
\hline
\end{tabular}

Note: Lags are chosen according to the BIC. *,**,*** denote significance at the 10\%, 5\%, and $1 \%$ levels, respectively. 
Table A.13. Results of the asymmetric error correction model with threshold cointegration based on weekly data (European, U.S. and Japan-Korean markets)

\begin{tabular}{|c|c|c|c|c|c|c|}
\hline & $\begin{array}{c}\text { U.K NBP } \\
\left(\Delta P_{t}^{1}\right)\end{array}$ & $\mathrm{JKM}\left(\Delta P_{t}^{3}\right)$ & $\begin{array}{c}\text { U.S. HH } \\
\left(\Delta P_{t}^{2}\right)\end{array}$ & $\mathrm{JKM}\left(\Delta P_{t}^{3}\right)$ & $\begin{array}{c}\text { Netherlands } \\
\text { TTF }\left(\Delta P_{t}^{2}\right)\end{array}$ & $\mathrm{JKM}\left(\Delta P_{t}^{1}\right)$ \\
\hline$\Delta N B P_{t-1}^{+}$ & $\begin{array}{c}0.112 \\
(0.092)\end{array}$ & $\begin{array}{c}0.066 \\
(0.046)\end{array}$ & & & & \\
\hline$\Delta N B P_{t-2}^{+}$ & $\begin{array}{l}-0.110 \\
(0.093)\end{array}$ & $\begin{array}{c}0.027 \\
(0.047)\end{array}$ & & & & \\
\hline$\Delta N B P_{t-1}^{-}$ & $\begin{array}{c}0.042 \\
(0.088)\end{array}$ & $\begin{array}{l}-0.035 \\
(0.044)\end{array}$ & & & & \\
\hline$\Delta N B P_{t-2}^{-}$ & $\begin{array}{c}0.035 \\
(0.087)\end{array}$ & $\begin{array}{c}0.048 \\
(0.044)\end{array}$ & & & & \\
\hline$\Delta J K M_{t-1}^{+}$ & $\begin{array}{l}-0.057 \\
(0.160)\end{array}$ & $\begin{array}{c}0.495 * * * \\
(0.080)\end{array}$ & $\begin{array}{c}0.077 \\
(0.118)\end{array}$ & $\begin{array}{c}0.509 * * * \\
(0.078)\end{array}$ & $\begin{array}{l}-0.071 \\
(0.141)\end{array}$ & $\begin{array}{c}0.472 * * * \\
(0.079)\end{array}$ \\
\hline$\Delta J K M_{t-2}^{+}$ & $\begin{array}{c}0.162 \\
(0.159)\end{array}$ & $\begin{array}{l}-0.031 \\
(0.080)\end{array}$ & $\begin{array}{c}0.023 \\
(0.118)\end{array}$ & $\begin{array}{l}-0.049 \\
(0.078)\end{array}$ & $\begin{array}{l}-0.026 \\
(0.139)\end{array}$ & $\begin{array}{l}-0.022 \\
(0.078)\end{array}$ \\
\hline$\Delta J K M_{t-1}^{-}$ & $\begin{array}{c}0.001 \\
(0.155)\end{array}$ & $\begin{array}{c}0.465 * * * \\
(0.078)\end{array}$ & $\begin{array}{l}-0.083 \\
(0.116)\end{array}$ & $\begin{array}{c}0.472 * * * \\
(0.077)\end{array}$ & $\begin{array}{c}0.046 \\
(0.138)\end{array}$ & $\begin{array}{c}0.456 * * * \\
(0.077)\end{array}$ \\
\hline$\Delta J K M_{t-2}^{-}$ & $\begin{array}{c}0.144 \\
(0.152)\end{array}$ & $\begin{array}{c}0.072 \\
(0.076)\end{array}$ & $\begin{array}{c}0.116 \\
(0.115)\end{array}$ & $\begin{array}{c}0.079 \\
(0.076)\end{array}$ & $\begin{array}{c}0.092 \\
(0.134)\end{array}$ & $\begin{array}{c}0.090 \\
(0.075)\end{array}$ \\
\hline$\Delta H H_{t-1}^{+}$ & & & $\begin{array}{c}-0.296 * * * \\
(0.102)\end{array}$ & $\begin{array}{l}-0.005 \\
(0.068)\end{array}$ & & \\
\hline$\Delta H H_{t-2}^{+}$ & & & $\begin{array}{l}-0.146 \\
(0.102)\end{array}$ & $\begin{array}{c}0.048 \\
(0.068)\end{array}$ & & \\
\hline$\Delta H H_{t-1}^{-}$ & & & $\begin{array}{c}0.339 * * * \\
(0.111)\end{array}$ & $\begin{array}{l}0.123^{*} \\
(0.074)\end{array}$ & & \\
\hline$\Delta H H_{t-2}^{-}$ & & & $\begin{array}{l}-0.139 \\
(0.111)\end{array}$ & $\begin{array}{c}0.064 \\
(0.074)\end{array}$ & & \\
\hline$\Delta T T F_{t-1}^{+}$ & & & & & $\begin{array}{l}-0.144 \\
(0.091)\end{array}$ & $\begin{array}{l}-0.082 \\
(0.051)\end{array}$ \\
\hline$\Delta T T F_{t-2}^{+}$ & & & & & $\begin{array}{c}0.024 \\
(0.092)\end{array}$ & $\begin{array}{c}0.062 \\
(0.052)\end{array}$ \\
\hline$\Delta T T F_{t-1}^{-}$ & & & & & $\begin{array}{c}0.216 * * \\
(0.094)\end{array}$ & $\begin{array}{c}0.165 * * * \\
(0.053)\end{array}$ \\
\hline$\Delta T T F_{t-2}^{-}$ & & & & & $\begin{array}{c}-0.166^{*} \\
(0.094)\end{array}$ & $\begin{array}{l}-0.054 \\
(0.053)\end{array}$ \\
\hline$E C M_{t-1}^{+}$ & $\begin{array}{c}0.034 \\
(0.032)\end{array}$ & $\begin{array}{l}-0.020 \\
(0.016)\end{array}$ & $\begin{array}{c}0.016 \\
(0.0023)\end{array}$ & $\begin{array}{l}-0.018 \\
(0.016)\end{array}$ & $\begin{array}{c}0.038 \\
(0.023)\end{array}$ & $\begin{array}{l}-0.019 \\
(0.013)\end{array}$ \\
\hline$E C M_{t-1}^{-}$ & $\begin{array}{c}0.026 \\
(0.026)\end{array}$ & $\begin{array}{l}-0.008 \\
(0.013)\end{array}$ & $\begin{array}{c}0.016 \\
(0.022)\end{array}$ & $\begin{array}{c}0.015 \\
(0.015)\end{array}$ & $\begin{array}{l}-0.030 \\
(0.037)\end{array}$ & $\begin{array}{l}-0.022 \\
(0.021)\end{array}$ \\
\hline Intercept & $\begin{array}{c}0.001 \\
(0.006)\end{array}$ & $\begin{array}{c}0.002 \\
(0.003)\end{array}$ & $\begin{array}{c}0.001 \\
(0.005)\end{array}$ & $\begin{array}{l}0.006^{*} \\
(0.004)\end{array}$ & $\begin{array}{l}-0.001 \\
(0.005)\end{array}$ & $\begin{array}{c}0.002 \\
(0.003)\end{array}$ \\
\hline
\end{tabular}

Note: Lags are chosen according to the BIC. *,**, *** denote significance at the 10\%, 5\%, and 1\% levels, respectively. 